\title{
Methods for online monitoring of air pollution concentration
}

\author{
Ionel Ioana and Francisc Popescu \\ "Politehnica" University of Timisoara \\ Romania
}

\section{Introduction}

In this chapter some major considerations of an environmental management by direct on line monitoring of the air quality, illustrated by examples, as experienced by the authors, are discussed. First the standard (reference) methods for the main pollutants are indicated, further some non-standard methods.

Atmospheric pollution is a major problem facing all nations of the world. Rapid urban and industrial growth has resulted in vast quantities of potentially harmful waste products being released into the atmosphere. The atmosphere is the largest imaginable chemical reactor in which pollutants may be converted into more harmful or harmless substances. Societies have been reluctant to accept, or have simply failed to recognise the limitations of the cleaning properties of the atmosphere and self-adaptation of the ecosystem Planet, with no remnant damages or preventing a non-equilibrium status. The consequences has been that air pollution has affected the health and wellbeing of people, has caused widespread damage to vegetation, crops, wildlife, materials, buildings and climate, and has resulted in depletion of the scarce natural resources needed for long-term economic development. In the past, the earth was considered virtually infinite, and little thought was given to the polluting effects of our dumping wastes. The atmosphere felt to be so vast that it could absorb any amount. However, over the past decades, several factors have come together to bring this attitude into sharp question. Along with the realisation that we are on an all too finite spaceship - the earth - the increasing population and technological base for our way of life and the increased sensitivity of our instruments for measuring pollution have all played a role in bringing about an awareness regarding the environment and its quality.

Air pollution adversely affects soil, water, crops, vegetation, human-made materials, buildings, animals, wildlife, weather, climate, and transportation, as well as reduce economic values, personal comfort and well being. More and more, in the present time of the society of knowledge, the population and the policy makers are convinced and engaged for preserving the biodiversity that is fundamental to human welfare and economic development, and plays a critical role in meeting human needs by maintaining the ecological processes on which our survival depends. Broad-scale ecological systems provide benefits such as clean air and fresh water that are needed by everyone, whether in urban or rural settings. 
As main sources for the pollution of air one recognises: the natural sources, and the man-made sources, in direct dependency to the energy consumption that is driven from the standard of comfort and industrial development, being influenced by the number of population, as well. It is not difficult to see that all of us are either directly or indirectly polluters and all of us share the disadvantages and cleanup costs of pollution generating activities, although often not in an equal and equitable manner.

In order to keep control over the quality of air the policy makers, in international co-operation mostly, decided to introduce specific regulations attesting the maximum admitted values as well the alert values. Thus, one controls both the emissions and the air quality, that represents a result of the transport in the air of the pollutants, in direct dependence to the topography and the weather conditions. Primary pollutants are those released directly from the source into the air in a harmful form. They are mostly result from combustion of classic C - containing nonrenewable fuels, and not only even the combustion is perfect, according to thermodynamic concepts. Secondary pollutants, by contrast, are modified to a hazardous form after they enter the air or are formed by chemical reactions as components of the air mix and interactive. Fugitive emissions are those that do not go through a smokestack. By far the most massive example of this category is dust from soil erosion, strip mining, rock crushing, and building construction (and destruction). Fugitive industrial emissions are also an important source of air pollution.

\section{Present state of art}

\subsection{Significance of the locations and sampling}

When carrying out air quality measurements it is important to define the problem precisely (measuring plan) and to choose accordingly the site locations, measuring stations and methods. Applying the most expensive measuring instrument is of no use if, e.g., the pollutant to be investigated is influenced during its sampling to such a degree that it either cannot reach the measuring instrument at all or not in its original state. When measuring pollutant gases in the air a difference between mobile measurements and stationary measurements stations is necessary. Mobile stations (laboratories) are measuring at random and changing locations, according to a plan, to determine the spatial distribution of the air pollutants, whereas stationary measurements continuously record the temporal distribution in few fixed points of a certain area. Stationary measurements must be carried out at representative points of the investigated area. It is recommended to know the spatial distribution of the ambient air pollutants which might be determined only with mobile measurements at the corner points of a $1 \times 1 \mathrm{~km}$ grid over the area to be investigated (Erste allg., 1986). Special guidelines have been drawn up so that the site locations for automatic measuring stations are chosen according to standardized criteria. Selection of the right sampling site can be of great importance for stationary as well as for mobile measurements. Guidelines have been drawn up so that in the measuring networks the site locations for automatic measuring stations are chosen according to standardized criteria. These guidelines are very important especially when planning on line in real time air quality measuring networks, i.e., when data are continuously transferred to a central station (RdSchr, 1983). Thus, selecting the site locations for ambient air quality measuring stations means to respect important guidelines in order to meet the general goal that the ambient air meaning that sample is representative of the area (Immissionsmessnetze in der 
Bundesrepublik Deutschland, 1987), (Projektgruppe Bayern, GSF-Bericht 25/87). Generally speaking, these conditions are specified by legislation, in each country, but general rules are at their origin. Some of these general rules refer to: (i) distance of measuring site to the closest flow obstacle must be twofold height or width of the obstacle's, (ii) sample suction should be placed below half of the mean building height, (iii) influence of local emission sources must be kept low meaning the distance to sources (industry, domestic furnaces, streets with heavy traffic) should be more than regularly $20 \mathrm{~m}$, and special investigation when industrial sources are situated nearby, are necessary. Further, a free flow accessibility of the sampling systems within a radius of less than $10 \mathrm{~m}$ and no flow obstacles such as trees or buildings must be assured, excluding by this mean the influence on measuring site by topographically caused local circulation. EU guideline requires that special aggressive pollutant gases (i.e. NO), must be measured continuously, particularly in locations with the suspected highest load risk, i.e., also near roads with heavy traffic, in street canyons, etc. The sampling system for gaseous pollutants consists generally of a sampling nozzle, a guidance tube, a central sampling tube, sampling connections leading from the central sampling tube to the individual measuring instruments and a fan or a pump. The sampling nozzle might be constructed as a pre-separator for particles and precipitation. The sampling line should extend generally $1 \mathrm{~m}$ beyond the station roof. In the standard measuring stations particle filtering in the sampling system is not provided in order to avoid possible reactions of the gases on the filters. Particle filters are only installed at the input of the instruments themselves (Laskus \& Bake 1976).

Within air quality investigations, pollutant concentration profiles must frequently be measured. Examples for this are the determinations of pollutant concentrations in and over special sites at different altitudes (Baumbach et al., 1987), (Kost \& Baumbach, 1985) or the registration of the concentration decline in the vicinity of streets, industrial areas with heavy traffic or intensive emissions (Esser, 1982), (Baumann, 1987). To be able to simultaneously or quasi-simultaneously measure the gas concentrations at several locations there is the possibility of sucking the air in via tubes and to conduct it to a set of measuring instruments with the help of a measuring gas change-over in short periods of alternation.

During measuring the gas (air) probe is sucked in through tubes, and an influencing of gaseous substances is generally to be expected even if the tube wall material is inert, e.g., from Teflon. Also it is best to use warmed up tubes, in order to avoid the condensation of vapor. This depends on the reactivity of the gases to be investigated. Examinations with long tube lines have shown that the component ozone is most prone to losses in the tube system whereby a clear dependency on the rate of flow through the tube is to be observed. The air sucked in must be filtered to avoid dust depositions on the admission section.

According to national standards and general international methods the main pollutants to be measured are: $\mathrm{NO}_{\mathrm{x}}\left(\mathrm{NO}, \mathrm{NO}_{2}\right), \mathrm{CO}, \mathrm{SO}_{2}, \mathrm{PM} 10, \mathrm{O}_{3}, \mathrm{TOC}$ (Total organic carbon) respectively VOC (Volatile organic compounds).

Fig. 1 shows a scheme of a set-up of such a measuring station. The measuring gas suction hoods and different meteorological measuring instruments are installed on a $10 \mathrm{~m}$ high altitude. The management and working methods are respecting the international standards SR EN ISO/CEI 17025:2005 (General features and competences), according to the fundamentals and definitions imposed by SR EN ISO 9000:2006. In addition to the instruments for the specific measurement of pollutants there are numerous other instruments for the recording of meteorological parameters such as wind direction and wind 
speed, temperatures, global radiation, duration of rain and bedewing, amount of rain etc., as well as an electronic controlled computer, to record, calculate and memorise the values. The computer also controls the valve timing and correctly stores the measured values according to the given valve position. Half-hourly mean values (or other mean values) are calculated and are stored in the memory or/and printed out. Further evaluation of the data is then carried out on a larger computing system. Some measuring stations work with direct data transmission to a central computing station. For reasons of safety the measured values are additionally recorded by multi-channel continuous-line recorders or multipoint recorders independently of the computer controlled measured value recording system. If the computer breaks down these recorder graphs can be evaluated if necessary.

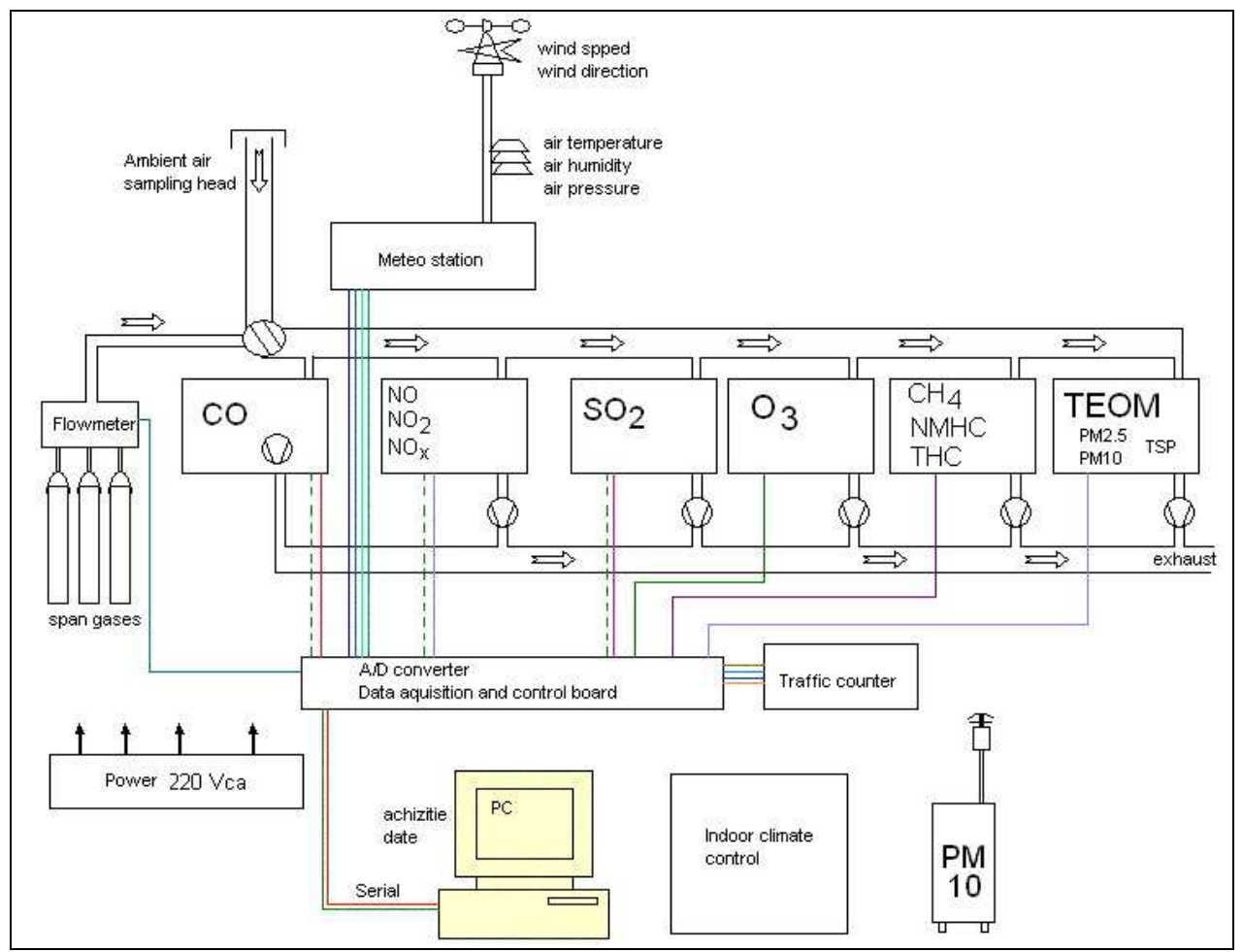

Fig. 1. Set-up of the sampling system of an air quality station with air suction through tubes and with calibration gas switching (www.mediu.ro).

In the example (Fig. 1.) also an optic open path device is included; this is an option not compulsory, for supplementary measuring possibilities, according non standardised methods. Monitors for $\mathrm{NO}_{x}$ detection from ambient air, based on the chemiluminescence's principle, according ISO 7996/1985, Monitor for the $\mathrm{SO}_{2}$ ambient air concentration, working in UV by applying the fluorescence method, according ISO/FDIS 10498, instruments for CO detection applying ND spectroscopy in IR, according ISO 4224, Sampling analyser LVS3 for the PM10 specie, based on the filtration and mass determination of a specific suspension by 
means of gravimetric principles, according EN 12341 are the basic standard main components. Mostly available are also an $\mathrm{O}_{3}$ measuring devices applying as measurement principle the UV photometry, according reference method: EN 14625:2005, and $\mathrm{CH}_{4}, \mathrm{NMHC}$ and THC instruments using the measurement principle of FID (flame ionization detection), reference method EN 12619:2002.

Calibration and adjusting are of major importance for the correctness of the measurements. Adjusting means setting or trimming a measuring instrument as accurately as possible, while calibrating signifies determining the deviation measured as compared to the accurate value or the value considered as such (DIN 1319, 1985). In air pollution measurements calibration conditions are set up with the help of calibration (ready made by special companies) gas mixtures. These are gas or gas mixtures having a composition predetermined with sufficient certainty by measuring basic parameters such as mass, volume, time, amount of substance (molar number) by applying independent analysis methods (Hartkamp et al., 1983). During calibration the calibration gas are entered into the measuring setup (measuring instrument), the values indicated are read and compared with the values of the calibration gases assumed correct, then the deviations are recorded. Frequently, calibrating a measuring instrument is accompanied by other measures such as maintenance, function control, trimming and others.

According (Hartkamp et al., 1983) the total of all calibration processes consists either of basic calibration, or routine calibration, and control calibration. The basic calibration provides the fundamental relationship between given calibration gas concentrations and recorded signals, and is called calibration function. In many instruments linear calibration functions are indicated. Routine and control calibrations ensure the validity of the calibration data of the basic calibration. This control verifies whether the data obtained by the basic calibration carried out last are still valid. The results of routine and control calibrations are yes-nodecisions. The principle of calibration gas production is based on the procedure of adding a known amount of the gas of interest to a known volume or volume flow of carrier gas (mostly $\mathrm{N}_{2}$ or air) in certain amount. The most convenient way of calibrating is with commercially available calibration gases in pressure gas cylinders (produced with static methods).

Basically, the instruments are connected to a common sample line and the measurements are taking place in the same time and for the same spot for all species. Because of the instruments high precision and accuracy the station must be equipped with calibration gases with a minimum of $\pm 1 \%$ uncertainty. The numeric values provided be instruments are collected by an PC data acquisition system and stored continuously for interpretation. The station indoor environment must be controlled in order to maintain a constant temperature for instruments.

The data acquisition system of the station is automatic and the data are stored in an ASCI file type format. The operator is using the data mainly to perform graphics for each pollutant and to compare their concentration with law regulated concentrations.

\subsection{Physical and Chemical Measuring Principles}

For the physical measuring methods a specific physical property of the pollutant is made use of as quantity to be measured. The air sample does not change materially during its measurement. Specific physical properties of the substances to be investigated are applied to which other components of the sample do not contribute. In chemical measuring methods the quantity to be 
measured is transformed into a condition with characteristic; measurable properties by a chemical reaction; during this chemical reaction the measured quantity changes.

Measuring processes based on a physical principle can generally be automated better for continuous processes, chemical methods usually being suitable for discontinuous measurements. Chemo-physical measuring principles are also applied. An essential principle which is primarily applied in the continuous measurement of gaseous pollutants is the excitation of molecules by adding energy. Excitation can be caused by exposure to radiation in different wave lengths, by generating high temperatures, e.g., via combustion, or by chemical reactions. Either the energy used for excitation or the energy released in another form is exploited for measurement. There are still further methods of excitation, e.g., excitation by electric, magnetic or nuclear forces. Methods of this type can be used for laboratory analyses of air pollutant samples collected. They are used less frequently, however, for direct measuring.

Passive sampling methods provide reliable, cost-effective air quality analysis, which gives a good indication of average pollution concentrations over a period of weeks or months. Passive samplers are so-called because the device does not involve any pumping. Instead the flow of air is controlled by a physical process, such as diffusion. Active sampling methods use physical or chemical methods to collect polluted air, and analysis is carried out later in the laboratory. Typically, a known volume of air is pumped through a collector (such as a filter, or a chemical solution) for a known period of time. The collector is later removed for analysis.

\subsection{Units}

A number of different units are used in expressing the concentrations of various species in the atmosphere (Ionel, 2000).

For gas phase species, the most commonly used units are parts per million (ppm), parts per hundred million (pphm), parts per billion ( $p p b)$, and parts per trillion (ppt). These units express the number of molecules of pollutant found in a million (106), a hundred million $\left(10^{8}\right)$, a billion (an American billion is 10, $a^{9}$ British billion is 1012) or a trillion (1012) molecules of air, respectively (Finlayson-Pitts \& Pitts, 1986).

Alternatively because numbers of molecules (or moles) are proportional to their volumes according to the ideal gas law $\left(p V=m R T\right.$, where $p$ - pressure in $\mathrm{Pa}, V$ - volume in $\mathrm{m}^{3}, m$ mass in $\mathrm{kg}, R$ is the gas constant expressed in $\mathrm{J} /(\mathrm{kg} \mathrm{K}), T$ - temperature in $\mathrm{K}$ ), one uses also the mass concentration. The conversion is carried out as follows:

$$
\begin{aligned}
& 1 \mathrm{mg} / \mathrm{m}^{3}=1 \mathrm{~cm}^{3} / \mathrm{m}^{3} \cdot \rho=1 \cdot \frac{\mathrm{cm}^{3} \text { pollutant } \cdot \mathrm{mg} \text { pollutant }}{\mathrm{m}^{3} \text { air } \cdot \mathrm{cm}^{3} \cdot \text { pollutant }} \\
& \rho=\text { gas density }=\frac{\mathrm{m}}{\mathrm{V}} \mathrm{kg} / \mathrm{m}^{3} \\
& \rho=\frac{\text { molar mass }}{\text { molar volume }} \mathrm{kg} / \mathrm{m}^{3} \text { or } \mathrm{g} / 1 \mathrm{or} \mathrm{mg} / \mathrm{cm}^{3} \\
& \rho=\frac{\text { molar mass }}{22.4} \mathrm{~kg} / \mathrm{m}^{3} \text { or } \mathrm{mg} / \mathrm{cm}^{3}\left(\text { at } 0{ }^{\circ} \mathrm{C}, 1,013 \text { mbar }\right) \\
& \rho=\frac{\text { molar mass }}{24} \mathrm{~kg} / \mathrm{m}^{3} \text { or } \mathrm{mg} / \mathrm{cm}^{3}\left(\text { at } 20^{\circ} \mathrm{C}, 1,013 \text { mbar }\right)
\end{aligned}
$$


The molar mass is specific to each chemical gas specie, according to its chemical formula. The molar volume is depending on the pressure and temperature values, considered by law as reference.

\section{Standard Measuring Methods for Air Pollutants}

\subsection{Photometry}

Photometry uses the absorption of infrared (IR), visible (VIS) or ultraviolet (UV) radiation by the gases as measuring effect. Wave length ranges are: IR $(1,000-10,000 \mathrm{~nm})$, VIS (400 $800 \mathrm{~nm}$ ), UV (approx. 200 - $400 \mathrm{~nm}$ ). In the visible and UV electrons are excited by radiation, in the IR range predominantly molecule vibrations but also rotations are activated. During this, the gases absorb energy in certain wave length ranges (absorption bands). The loss of radiation intensity caused by this is consequently measured.

Fig. 2 shows the principle of a photometer that consists of a radiation source (lamp), having a focused beam of light falling through a cell on a radiation detector. The latter transforms the beam into an electric signal of proportional intensity. The loss of radiation intensity due to the absorption of the measuring gas is - when frame conditions are constant - a measure for its concentration.

The interrelationships of radiation absorption are described by the Lambert-Beer law:

$$
\begin{gathered}
I=I_{0} \cdot e^{-\varepsilon \cdot C \cdot 1} \\
\frac{I}{I_{O}}=T=\frac{1}{E} \\
E=\ln \frac{I_{O}}{I}=\varepsilon \cdot C \cdot l
\end{gathered}
$$

where $I_{0}$ is the intensity of entering radiation (intensity of light for the reference), $I$ the intensity of exiting radiation (intensity of light for the sample), $T$ stands for the transmission, $\varepsilon$ for the extinction coefficient (dependent on wave-length), $C$ for the concentration of gas or pollutant, 1 for optical path-length of the cell measurement, $E$ for extinction (nondimensional) of the absorbing substance inverse logarithm of the transmission $\mathrm{T}$.

Most $I R$ photometers function as so-called non-dispersive instruments (NDIR), i.e., radiation is emitted in the entire IR range. There is no spectral splitting of the IR radiation emitted by the radiation source. Selectivity is achieved by installing a radiation detector filled with the component to be measured. This type of detector is possible only in the IR range, as the lifespan of the molecules excited by IR radiation is so long that the excitation energy can be released via molecule collisions as thermal energy. 


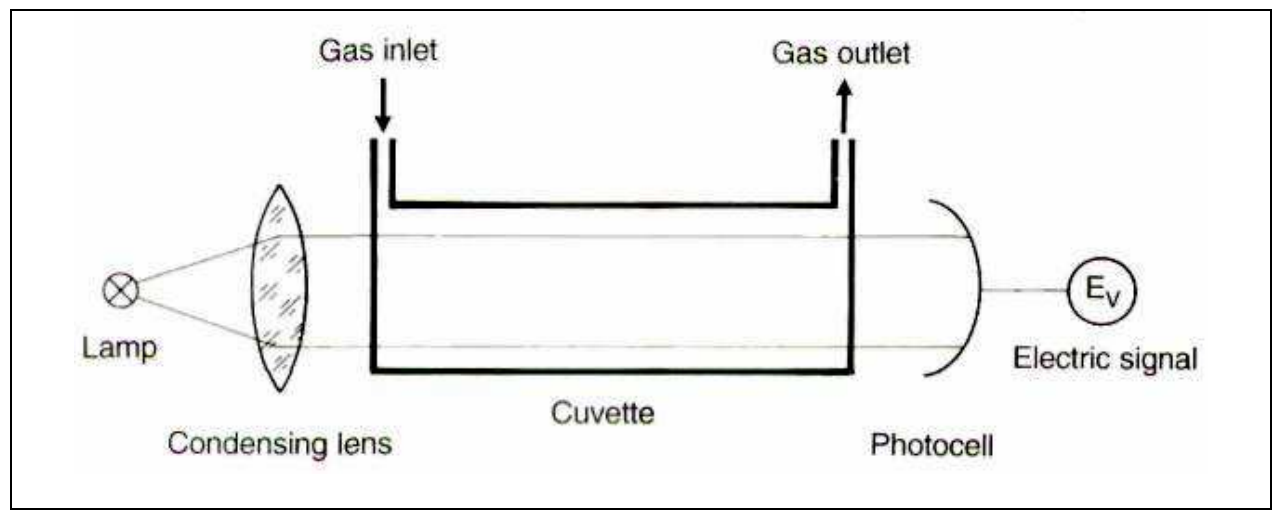

Fig. 2. Principle of a photometer (Baumbach, 1997).

Extinction $\mathrm{E}$ as a measure of the radiation absorption of a gas (or also of a liquid) is thus dependent on the properties of the gas (extinction coefficient epsilon), on the concentration $c$ and on the optical path-length 1 which the beam of light must pass through. If ambient conditions are constant, e for a gas is constant. If 1 is also kept constant, then extinction $E$ is directly dependent on the concentration of the gas to be measured.

In practice it is not sufficient to form the logarithm of the ratio of intensity $\mathrm{I}_{0}$ in and intensity I out and to thus determine extinction $E$. Even without the presence of the component to be measured the instruments absorb radiation, e.g., via optical windows and the gases to be investigated. Thus, even without the presence of the component to be measured, radiation in is not equal to radiation $\mathrm{I}_{0}$ out. This blank absorption must generally be determined experimentally.

NDIR instruments are primarily used for emission measurements; analyzers are mainly suitable for the determination of the gases $\mathrm{CO}, \mathrm{CO}_{2}$, NO, SO $, \mathrm{H}_{2} \mathrm{O}, \mathrm{CH} 4, \mathrm{C}_{2} \mathrm{H}_{6}$, and many other hydrocarbons. For $\mathrm{CO}$ and $\mathrm{CO}_{2}$, NDIR photometry is the most commonly used measuring technique, which is also unrivalled in its application for the measurement of these gases in the ambient air range.

As shown in the Fig. 3, the instruments for $\mathrm{CO}$ measurements uses the modulation effect that occurs with infrared absorption of sample gas itself when sample gas and zero gas are alternately sent to its cell at a certain flow rate using a solenoid valve which is actuated at a frequency of $1 \mathrm{~Hz}$. Unless the gas concentration of the measured component is changed in the cell, the output from the detector essentially becomes zero, therefore, the zero drift dose not occur. Since the instrument also uses the AS-type detector, extremely high-accuracy results are obtained without any effect of the interference component.

The radiation source is an infrared radiation emitter. The radiation - modulated by a chopper - passes a chamber containing the probe and in parallels a chamber containing a reference gas. To reduce the influence of interfering gases optical filters are used. The content of the measurement cell receives periodically infrared radiation with different strength, which results in different temperature and pressure effects. The pressure effects are hence transferred to electrical signals by a sensor, and this signal correlates to the measured $\mathrm{CO}$ concentration. Some systems use the pressure waves for detection, while others use directly the IR receiving an optical detector to measure the $\mathrm{CO}$ concentration. 


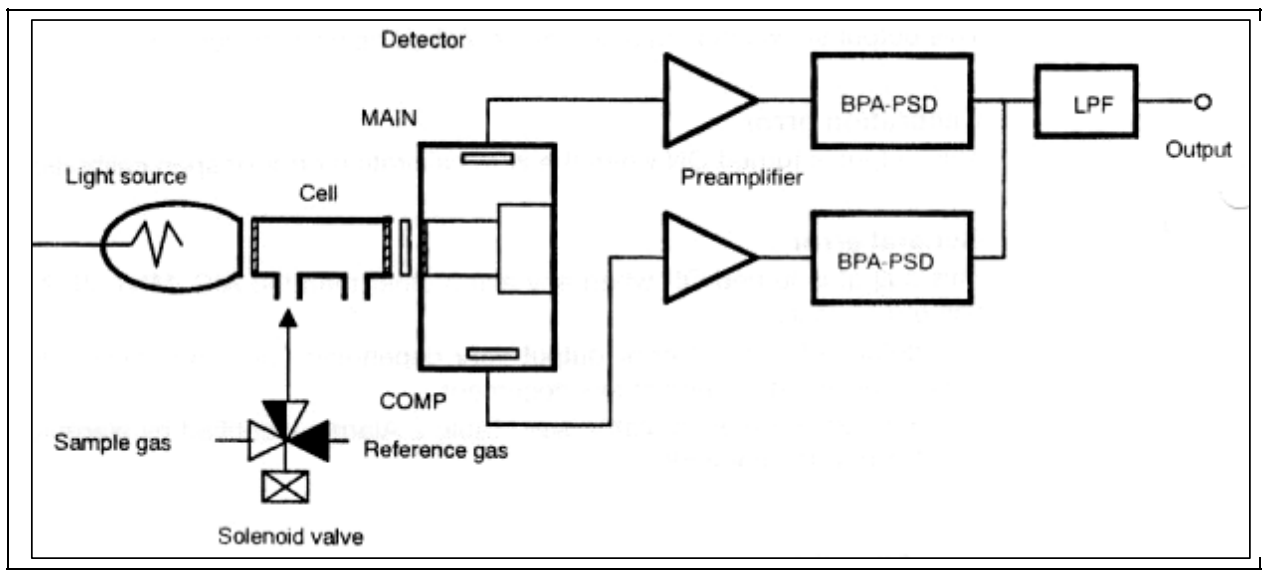

Fig. 3. CO monitoring device schematic (Horiba, User manual)

There are gases with relatively narrow UV absorption bands, e.g., $\mathrm{NO}$ and $\mathrm{NH}_{3}$. Other gases, however, absorb UV radiation in a wider band. To be able to obtain selective measurements certain stratagems are to be applied. A first selection is made by choosing the right UV lamp. Depending on their metal or gas fillings UV lamps have certain emission spectra. Therefore one uses lamps with emission bands which best correspond to the absorption bands of the measuring components or which lie within the absorption bands as clearly defined lines. Besides soiled cells and lamps with fluctuating intensities, they also lead to high and fluctuating reference values $1_{0}$ of the radiation and thus to high blank values of extinction. There are different possibilities of compensating for the blank extinctions and of receiving corrected reference radiation intensity $\mathrm{I}_{0}$ and will be outlined using the example of UV-photometric measurement of NO.

An UV absorption photometer for NO was developed as shown schematically in Fig. 4 (Hartmann \& Braun, 1982), (FVLR, 1979). In a hollow cathode lamp filled with nitrogen and oxygen at reduced pressure, excited NO molecules are formed in an electrical discharge. The energy of the excited molecules is dissipated by emission of characteristic luminescence radiation. The source of radiation is selective; it produces an emission range which corresponds precisely to the absorption range of NO in the measuring cell. This is called resonance absorption. One peculiarity of the radiation excited by electrical discharge is that two groups of NO-specific lines are emitted, i.e.: (i) "cold" emission lines - this is the group absorbed by the NO to be determined in the measuring cell (measuring radiation), (ii) "hot" emission lines - that group of radiation showing lines in the neighboring range and meeting the detector not influenced by $\mathrm{NO}$ (reference radiation).

The radiation is modulated by a chopper wheel and passed through the measuring cell via a condensing lens. It reaches the radiation detector, a photomultiplier, via an interference filter where interfering radiation is removed. If NO is present in the measuring cell, then the radiation is reduced by resonance absorption (extinction E) according to the Lambert-Beer law. For this measuring technique the blank value of extinction $\mathrm{E}_{0}$ is compensated for by alternately setting the chopper wheel to a position where all radiation (hot and cold emission lines) is passed through and to a position with a gas filter. 


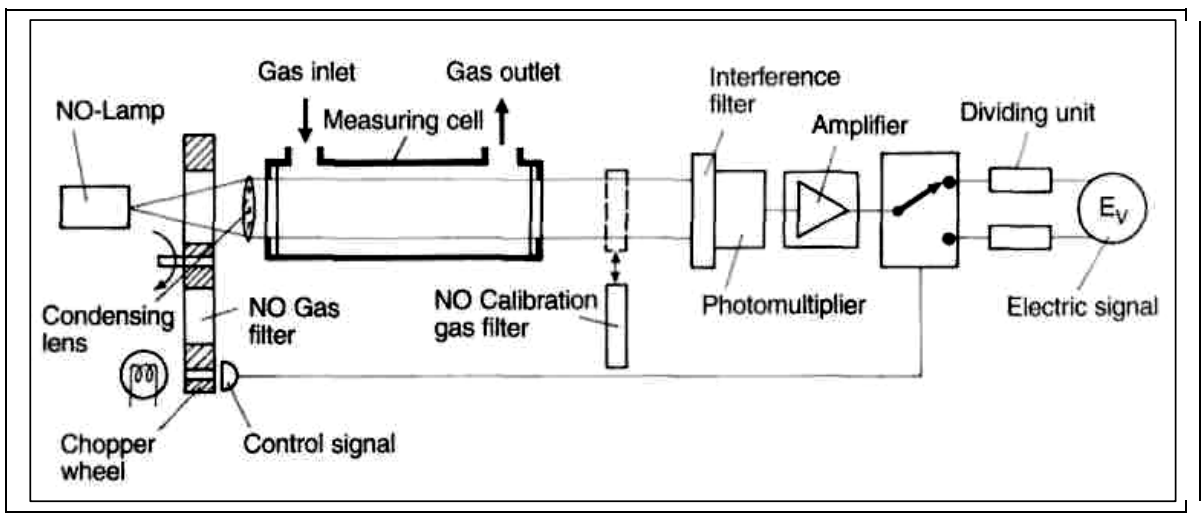

Fig. 4. Diagram of a UV gas analyzer for the detection of $\mathrm{NO}$ with blind value compensation by wavelength comparison (FVLR, 1979).

The gas filter contains NO in high concentrations which completely absorbs the cold emission lines. The hot emission lines, however, which are in the immediate neighborhood range, pass through it as reference radiation. Just like the measuring radiation they are influenced by the in-line optics, by the cell windows but mainly by the wide-banded interfering components to produce the intensity reference value $\mathrm{I}_{0}$ at the photomultiplier.

Fig 5 presents an ozone instrument that performs a dry analysis of ozone, on continuous basis.

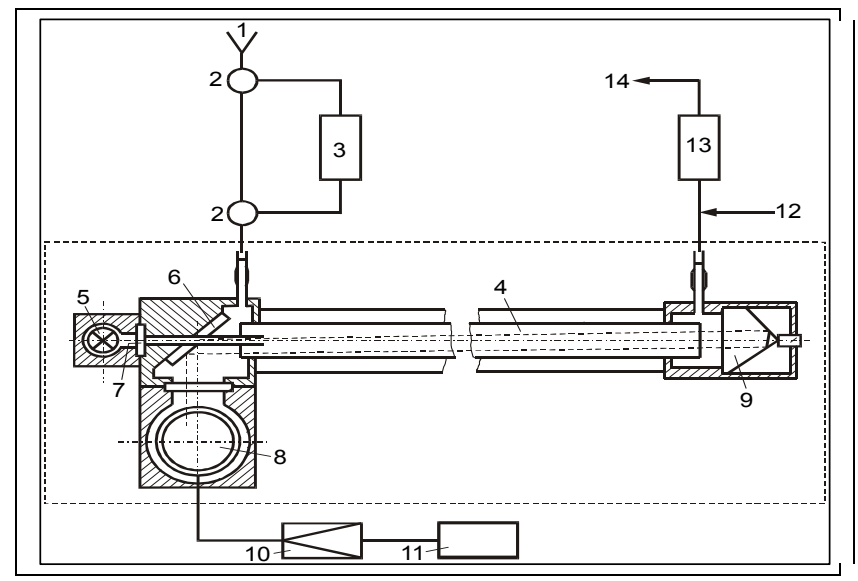

Fig. 5. $\mathrm{O}_{3}$ monitoring device schematic (Horiba, User manual) 1 - Sample intake, 2 - Three way valve, 3 - Ozone generator (internal calibration), 4 - Measurement cell, 5 - Hg-Low pressure lamp, Mirror, 6 - Interference filter, 7 - Photo multiplier, 8 - Quartz - triple prisms, 9 - Amplifier, 10 - Display, 11 - Exit gas sample, 12 - Charcoal, 13 - Excess air exit. 


\subsection{UV Fluorescence}

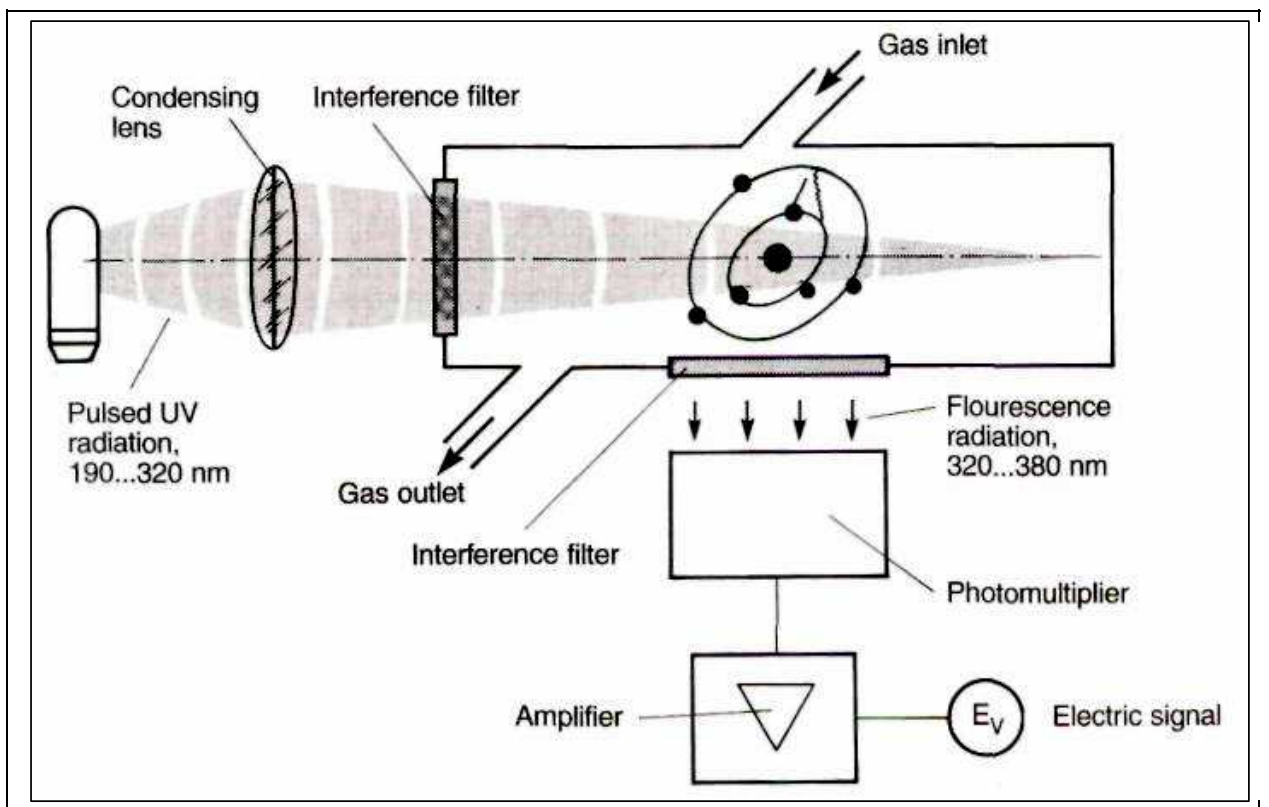

Fig. 6. Principle of UV fluorescence measurement (Zolner, 1984).

UV fluorescence is a measuring technique related to photometry. The measuring gas is also exposed to radiation. However, it is not the radiation absorption which is measured but a luminous phenomenon (fluorescence) which is caused by the excitation of molecules through UV radiation of a certain wavelength. The measuring principle is, e.g., applied in $\mathrm{SO}_{2}$ ambient air measurement, presented in Fig. 6.

The air sample is exposed to UV radiation in the wavelength range of $190-320 \mathrm{~nm}$. If present, $\mathrm{SO}_{2}$ gives off a fluorescence radiation of $320-380 \mathrm{~nm}$. Due to an interference filter only a radiation of this wavelength is recorded by the detector (photomultiplier); thus, the measuring principle is strictly selective. The higher the $\mathrm{SO}_{2}$ concentration, the greater the fluorescence.

One interference in this measuring technique is that other components can absorb the energy of the excited $\mathrm{SO}_{2}$ molecules, thus reducing the fluorescence yield. This interfering effect is known particularly from water vapor and hydrocarbons. By interposing a permeation gas exchanger an elimination of the interfering components from the measuring gas is attempted. Measuring instruments operating according to this principle are used for both $\mathrm{SO}_{2}$ air quality measurements as well as for $\mathrm{SO}$ emission measurements. In emission measurements the interferences are higher due to the higher concentrations of the interfering components. Air quality measurement instruments operate very stably as far as zero point and sensitivity drift are concerned and as long as the intensity of the UV lamp remains constant.

The reference method for $\mathrm{SO}_{2}$ measurements is the ultraviolet fluorescent method (UVF). 
When a sample is irradiated with ultraviolet ray $(215 \mathrm{~nm}), \mathrm{SO}_{2}$ emits the light of a different wavelength (peak: $320 \mathrm{~nm}$, range: $240 \mathrm{~nm}$ to $420 \mathrm{~nm}$ ) from that irradiated. The former, irradiated light is referred to as excitation light, and the later, emitted light is referred to as fluorescence. The method to obtain sample concentrations by measuring the fluorescence intensity is called the fluorescence method. In the fluorescence method, fluorescence, which radiates in all directions, is usually detected at the right angles to the excitation light in order to' prevent interference by the excitation light.

When excitation light is irradiated and absorbed following processes take place:

Process 1: Absorbing and process excitation.

$$
\mathrm{SO}_{2}+\mathrm{hv}_{1}->\mathrm{SO}_{2}{ }^{*}
$$

There are three ways by which the $\mathrm{SO}_{2}{ }^{*}$ loses its excitation energy.

Process 2: Fluorescence process: Excitation energy is emitted as fluorescence.

$$
\mathrm{SO}_{2}{ }^{*} \stackrel{k f}{\longrightarrow} \mathrm{SO}_{2}+\mathrm{Kv}_{2}
$$

Process 3: Dissociation process: Excitation energy is used for dissociation.

$$
\mathrm{SO}_{2}{ }^{*} \stackrel{k d}{\longrightarrow} \mathrm{SO}+\mathrm{O}
$$

Process 4: Quenching process: Excitation energy is lost by collision with surrounding molecules, $\mathrm{M}$.

$$
\mathrm{SO}_{2}{ }^{*}+\mathrm{M} \stackrel{k q}{\longrightarrow} \mathrm{SO}_{2}+M
$$

Practically, the excitation energy is lost resulting from the confluence of these three processes. Fig. 7 presents the schematic diagram of a $\mathrm{SO}_{2}$ measurement device.

The sample gas is continuously drawn into a cylindrical Teflon-coated reaction cell at near ambient pressures. The atmospheric gas is irradiated by UV light that has been mechanically modulated and filtered to $214 \mathrm{~nm}$. The fluorescent secondary emission of the SO2 molecules present in the gas is measured by a photo-multiplier tube (PMT). The PMT is located at $90^{\circ}$ from the UV lamp source on the axial centre line of the reaction cell. The filtered UV light passes through a collimating lens that focuses the light energy at the centre of the cell. The PMT is optically tuned to measure the fluorescent emission and outputs the signal through an amplifier to a synchronous demodulator. Simultaneously, the UV light source constancy is measured by a reference photo-detector tube, located directly across the reaction cell from the lamp. The light travel down an optically-designed dump to the photo tube, whereupon is output is amplified and processed through a nearly identical synchronous demodulator. The mixer board electronics then uses this signal to compensate for any variation in the UV light source. 


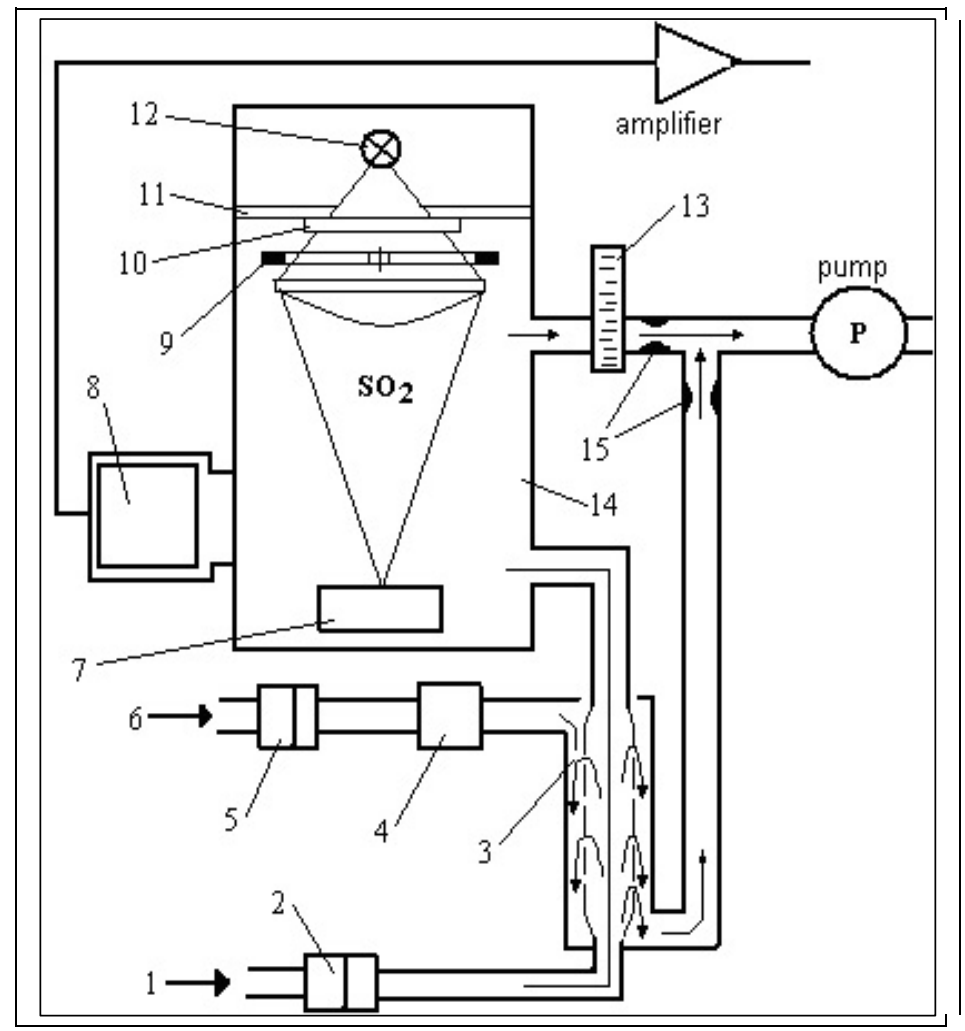

Fig. 7. $\mathrm{SO}_{2}$ monitoring device schematic according UV fluorescence principle (Baumbach, 1997).

\subsection{Chemiluminescence}

Chemiluminescence is related to UV fluorescence. The difference between the two is that in chemiluminescence molecules are not excited by UV radiation, but are excited by a chemical reaction. Thus, the measuring principle is a chemo-physical one. The intensity of the radiation created is a measure for the concentration of the reacting gas in a mixture of gases, if the external conditions (pressure, temperature and volume flow of the measuring gas) are kept constant. Just as is the case in UV fluorescence, the radiation created is recorded by a photomultiplier acting as radiation detector and is transformed into an electric signal. This method is used mainly for measuring $\mathrm{NO}, \mathrm{NO}+\mathrm{NO}_{2}$ (i.e., $\mathrm{NO}_{x}$ ) and $\mathrm{O}_{3}$.

To measure the $\mathrm{NO}$ and $\mathrm{NO}_{2}$ concentration into the atmosphere the TÜV (EU) and U.S. EPA requirements are fulfilled only by chemiluminescence's method. The instrument must provide continuous and unattended monitoring of $\mathrm{NO}, \mathrm{NO}_{2}$ and $\mathrm{NO}_{\mathrm{x}}$ with individual determinations and high reliability and accuracy. An internal $\mathrm{NO}_{2}$ to $\mathrm{NO}$ converter permit $\mathrm{NO}_{x}$ analysis and an integral ozone supply system which puts filtered, dehumidified ambient air through an ozonator to generate the ozone necessary for reaction with NO to give chemiluminescence's reaction. The instrument must have a flow-chopping modulation system to give continuous NOx and NO analysis. With this system, the sample gas is divided into two separate lines. One sample gas line passes through the $\mathrm{NO}_{2}$ to $\mathrm{NO}$ 
converter, while the other leads directly to the detector. Also a permeation tube in which only moisture is passed through is used for the sample line is needed. This tube functions so that an influence from the moisture is reduced by minimizing difference of moisture concentration between sample gas and reference gas.

Inside the reaction chamber $\mathrm{NO}$ reacts with ozone to form $\mathrm{NO}$. The $\mathrm{NO}_{2}$ is excited to a higher electronic state. This chemiluminescence's is measured through an optical filter by a photodiode. The modulated hybrid signal from the detector is demodulated to give continuous $\mathrm{NO}_{x}$ and $\mathrm{NO}$ signals at the same time. The $\mathrm{NO}_{2}$ concentration is given by subtraction of $\mathrm{NO}$ from $\mathrm{NO}_{x}$.

$$
\begin{gathered}
\mathrm{NO}+\mathrm{O}_{3} \rightarrow \mathrm{NO}_{2}{ }^{*}+\mathrm{O}_{2} \\
\mathrm{NO}_{2}{ }^{*} \rightarrow \mathrm{NO}_{2}+h v
\end{gathered}
$$

Filtered sample gas is divided into lines 1 and 2. In line 1, the sample gas flows through an integral converter which reduces $\mathrm{NO}_{2}$ to $\mathrm{NO}$. In line 2, the sample gas remains as it is. The sample gas is switched to NO line, reference line, NO line and to reference line again by the solenoid valve with $0.5 \mathrm{sec}$ interval. Then it is introduced into respective reaction chamber. Luminescence due to reaction of the sample and $\mathrm{O}_{3}$ occurred in the chamber is detected by a photodiode. By electrically processing the output of photodiode, it is possible to take out continuous signal in NO line and NO line respectively. Flow to the detector unit is controlled by capillaries. Ozone is supplied to the reaction chamber at a constant rate by an internal ozonator which uses dehumidified ambient air as feed gas. The dryer unit has two dryer cylinders. When one cylinder is under operation, the other is regenerated. For regeneration, first heat the tube to $120^{\circ} \mathrm{C}$ for 135 minutes to evaporate all the water, and then cool the tube for 45 minutes. It is possible to perform continuous drying by changing over the line of use and regeneration every 180 minutes.

According to the same chemiluminescence reaction as in the case of the NO measurement, ozone could be measured by its reaction with NO. A better and more inexpensive reaction partner for ozone, however, is ethane $\left(\mathrm{C}_{2} \mathrm{H}_{4}\right)$ :

$$
\begin{gathered}
\mathrm{O}_{3}+\mathrm{C}_{2} \mathrm{H}_{4} \rightarrow \mathrm{O}_{2}+\mathrm{C}_{2} \mathrm{H}_{4} \mathrm{O}^{*} \\
\mathrm{C}_{2} \mathrm{H}_{4} \mathrm{O}^{*} \rightarrow \mathrm{C}_{2} \mathrm{H}_{4} \mathrm{O}+h v \quad(300 \ldots 600 \mathrm{~nm})
\end{gathered}
$$

During this reaction chemiluminescence radiation is once again formed to be measured analogous to NO determination. The sole disadvantage of this ozone measuring technique is that ethane is required which is only available from a gas cylinder. As it is a flammable gas, this measuring technique is regarded with disfavor in air quality measuring stations and has given way increasingly to UV photometry. In the matter of interference and susceptibility to faults the chemiluminescence method is superior to UV photometry.

Fig. 8 gives the basic schematic of one $\mathrm{NO}_{x}$ analyzer. 


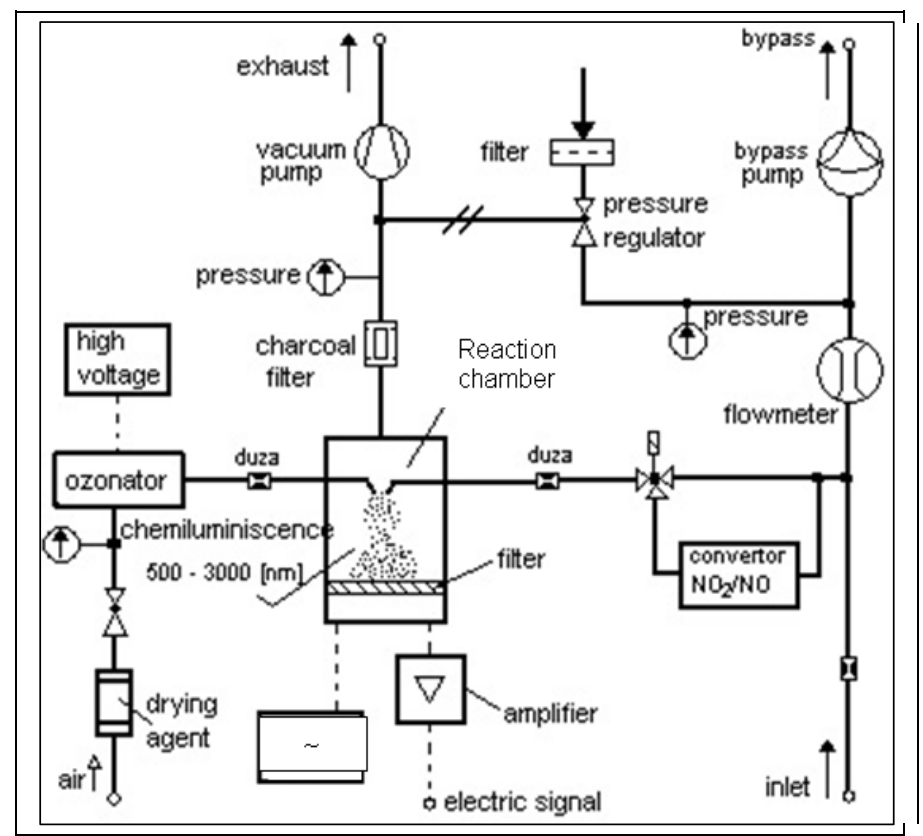

Fig. 8. $\mathrm{NO}_{\mathrm{x}}$ monitoring device schematic (HORIBA AP370 User manuals).

\subsection{Flame Photometry and Ionization}

In flame-photometry atoms are excited in a flame and made to luminescence. The spectral line of the atom of interest is filtered out from the radiation of the flame via an interference filter and measured with a photomultiplier. In gas analyses this process is used mainly for sulfur measurements, but it is also suitable for measuring phosphorous compounds. In sulfur measurement, however, the flame-photometric effect is not based on an atom emission but on a recombining of sulfur atoms whereby excited $S_{2}^{*}$ molecules are formed which pass into their basic state under a light emission of approx. $320 \mathrm{~nm}-460 \mathrm{~nm}$. With an optical filter a wave length of $394 \mathrm{~nm}$ is chosen for sulfur detection (Birkle, 1979).

The total sulfur content of the air, mainly $\mathrm{H}_{2} \mathrm{~S}$ and $\mathrm{SO}_{2}$, is primarily measured. If individual compounds are to be identified, then single gases must be removed by absorption and adsorption filters prior to measuring. This process is distinguished by a high sensitivity (low detection limit!) and by a very brief response time. Therefore measuring devices working on this principle are used, e.g., for air quality measurements with aircraft (Paffrath, 1985). Owing to the fact that hydrogen is required as an auxiliary gas for generating the flame inside the device the flame photometer is used less frequently in stationary air quality measuring stations. It is not common practice to use it for emission measurements as the concentrations to be measured are too high and there are too many interfering components (quenching).

Gases can be ionized more or less easily by the addition of energy. For gas analyses the ionization of organic molecules in flames (flame ionization) has gained the greatest significance. Ionization by radiation of radioactive substances in detectors, e.g., in gas chromatography, is also applied (Kaiser, 1965). 


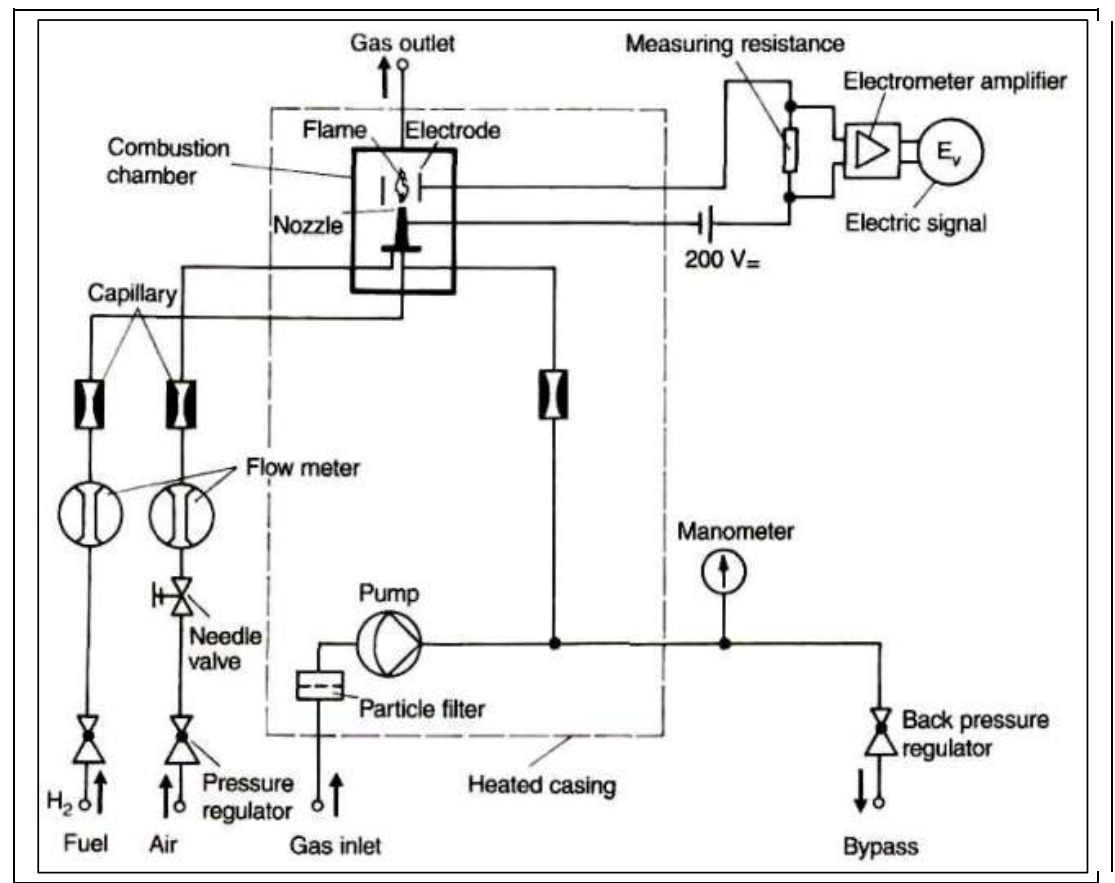

Fig. 9. Diagram of a flame ionization detector (FID) (Kaiser, 1965).

The so-called flame-ionization detector (FID) was originally developed for gas chromatography. Nowadays, it is also used as the most important measuring device for the continuous recording of organic substances in exhaust gases or in ambient air.

The measuring principle of the FID is classic and will be summarized here with the help of Fig 9.

The hydrogen flame burns out of a metal nozzle which simultaneously represents the negative electrode of an ionization chamber. The positive counter-electrode is fixed above the flame, e.g., as a ring. Between the two electrodes direct voltage is applied. The ion current is measured as a voltage drop above the resistor $\mathrm{W}$. The measuring gas is added to the burning gas shortly before entering the burner nozzle. The air required for combustion flows in through a ring slot around the burner nozzle.

For stable measuring conditions it is essential that all gases - combustion gas, combustion air and measuring gas - are conducted into the flame in constant volume flows. For this, all gas flows are conducted via capillaries. Constant pressures before the capillaries ensure a constant flow. Sensitive pressure regulators for combustion gas and combustion air are used to achieve this fine-tuning. The measuring gas is pumped past the capillary in the bypass in a great volume flow. Pressure is kept constant by the back pressure regulator, so that a constant partial flow reaches the flame via the capillary. Most FID's operate with overpressure, i.e., the measuring gas pump is located before the capillary. To avoid condensation of the hydrocarbons to be measured almost all instruments can be heated to $150-200{ }^{\circ} \mathrm{C}$. Heating includes the particle filter and the measuring gas pump; in most cases, 
particularly with warm exhaust gases, a heated sampling line is also used from measuring gas sampling to the measuring instrument.

Hydrocarbon compounds are oxidized in the flame with ions being formed as an intermediate product. In a certain range of the accelerating voltage the strength of the ionization current is in first approximation directly proportional to the amount of $\mathrm{C}$ atoms of the burned substance. Thus, an FID basically responds to all hydrocarbons and measures their total sum. Corresponding to the number of carbon atoms, larger molecules with many $\mathrm{C}$ atoms produce a higher signal than smaller molecules with a small number of $\mathrm{C}$ atoms. Ionization energy does not only stem from the flame's energy, but mainly from the oxidation energy of the carbon. Accordingly partially oxidized hydrocarbons provide a weak detector signal, completely oxidized hydrocarbons no signal at all; $\mathrm{HCHO}, \mathrm{CO}$ and $\mathrm{CO}_{2}$, e.g., are not detected. If exhaust gases predominantly consist of mixtures of pure, i.e., non-oxidized or halogenated hydrocarbons, the FID provides a signal nearly proportional to the carbon miss content of the exhaust gas.

The reference method for $\mathrm{HC}$ (hydrocarbons) measurements (including $\mathrm{CH}_{4}$ methane and NMHC - non-methane hydrocarbon) is the flame ionization method (FID). The principle of this method is represented in figure 10.

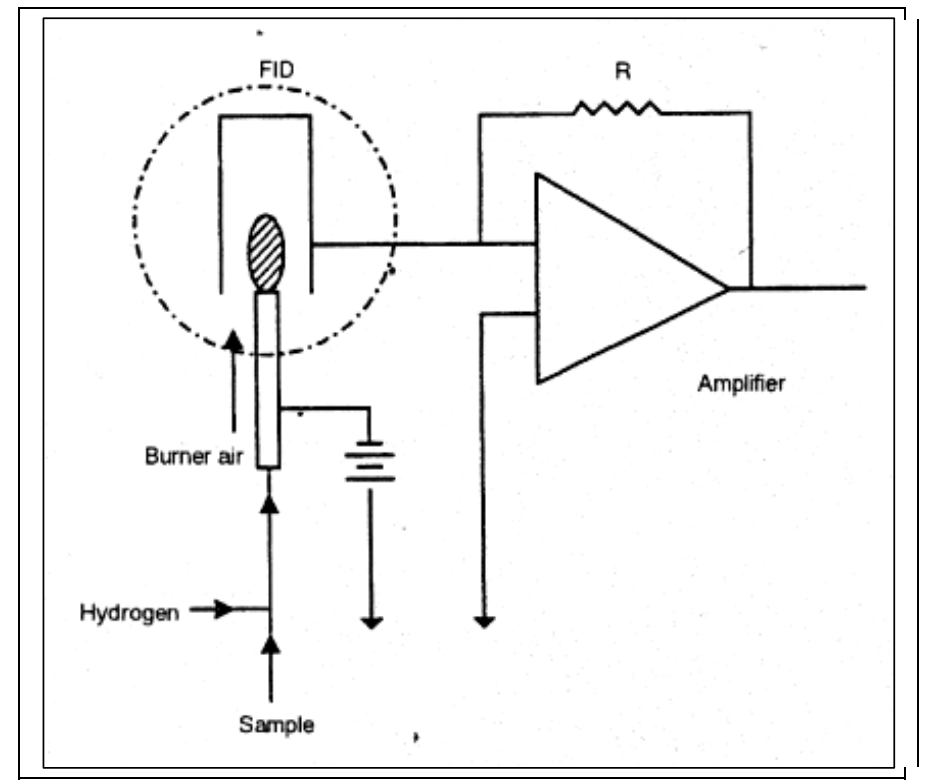

Fig. 10. FID monitoring device schematic for (Horiba, User manual)

When hydrocarbon is introduced to hydrogen flame, the high-temperature energy at the jet nozzle tip ionizes the hydrocarbon molecules. In this time, applying a direct-current voltage between two electrodes that face each other across the flame generates a minute ion current, proportional to the carbon number of the ionized hydrocarbon. The total hydrocarbon can be measured by passing this ion current through a high resistance to convert it to voltage. The sampled gas is divided in two flows: one is used for $\mathrm{CH}_{4}$ concentration measurement by removing $\mathrm{HC}$ other than $\mathrm{CH}_{4}$. The other is used for THC concentration measurement 
directly. These two sample gases and zero gas are sent to the analyzer alternately to measure $\mathrm{CH}_{4}$ and THC concentrations. Besides, NMHC concentration is obtained by subtracting $\mathrm{CH}_{4}$ from THC.

\subsection{Measuring Methods for Particulate Matter}

When examining particulate matter in ambient air the following factors must be taken into account: (i) total mass concentration of the particulate matter, (ii) concentration of fine particles, (iii) size distribution, (iv) chemical composition.

In the air quality range particle sedimentation as well as non-sediment suspended particulate matter is of interest, particularly the latter, as it is respirable and can thus carry pollutants into the human body.

Particulate matter (PM) is a medium which consists of a lot of different substances regarding chemical composition and size distribution. Relevant for human health are PM with an aerodynamic diameter smaller $10 \mu \mathrm{m}$ (PM10) with a tendency to smaller sizes, e.g. PM2.5.

PM's could be measured with many techniques but the most relevant are TEOM devices and SMPS (Scanning Mobility Particle Seizer) gravimetric techniques.

The TEOM instrument is a true "gravimetric" instrument that draws ambient air through a filter at a constant flow rate, continuously weighing the filter and calculating near real time mass concentrations.

When the instrument samples, the ambient air stream first passes through an optional sizeselective inlet, and continues down the heated sample tube to the mass transducer. Inside the mass transducer, this sample stream passes through a filter made of Teflon-coated borosilicate glass. The instrument measures the mass of this filter every 1.68 seconds. The difference between the filter's initial weight (as automatically measured by the instrument when data collection begins) and the current mass of the filter gives the total mass of the collected particulate. These instantaneous readings of total mass are then averaged using a user selectable averaging time to reduce noise. Next, the mass rate is calculated by computing the increase in the averaged total mass between the current reading and the immediately preceding one, and expressing this as a mass rate in $\mathrm{g} / \mathrm{sec}$. This mass rate is smoothed to reduce noise. Finally, the mass concentration in $\mu \mathrm{g} / \mathrm{m}^{3}$ is computed by dividing the mass rate by the flow rate. Internal temperatures in the instrument are controlled in order to minimise the effects of changing ambient conditions. The sample stream is preheated before entering the mass transducer (usually to $50^{\circ} \mathrm{C}$ ) so that the sample filter always collects under conditions of very low (and therefore relatively constant) humidity. 


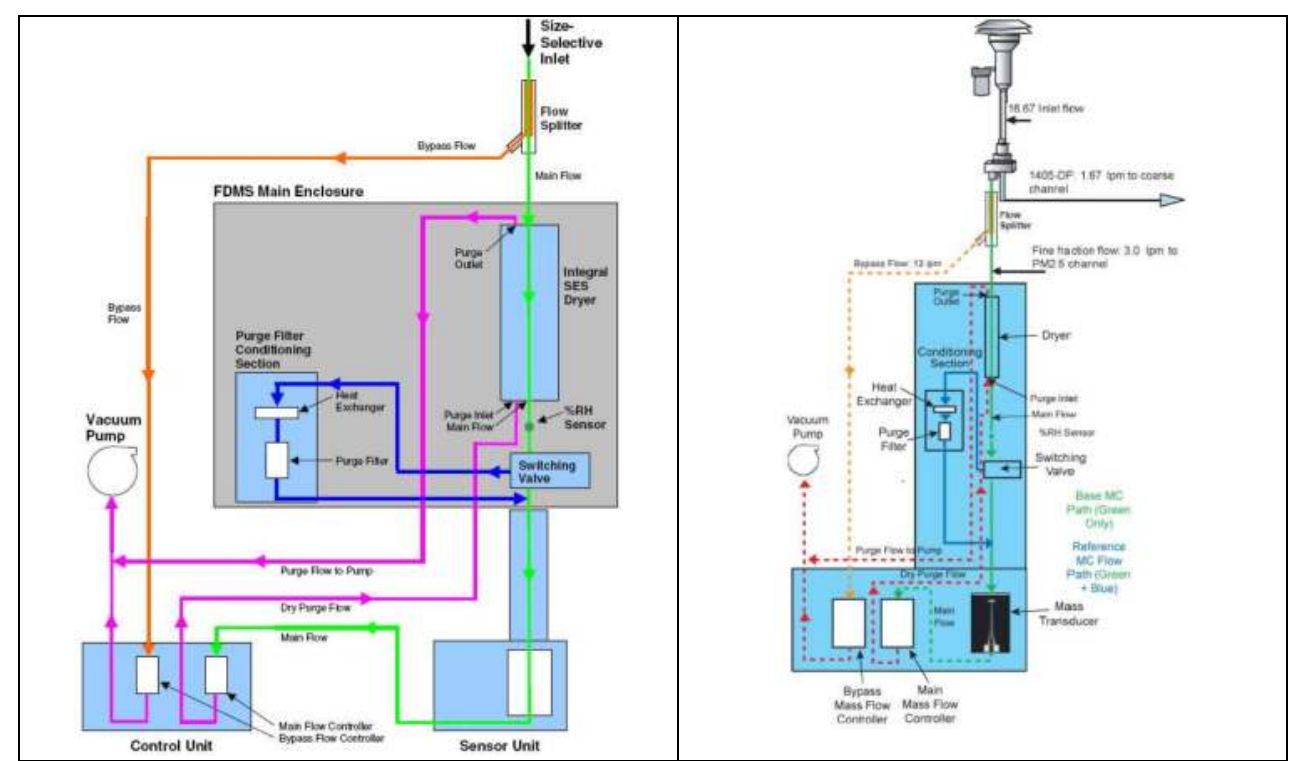

Fig. 11. PM measurement device TEOM (Thermo Scientific, User manual TEOM Monitor, Series 1400ab)

Fig. 11 is a schematic diagram showing the flow of the sample stream through the instrument in the case of a PM-10 configuration. The TEOM Monitor measures PM-10 or PM-2.5 mass concentrations and consists of a TEOM mass sensor and control unit in a network ready configuration.

The particle size separation at $10 \mu \mathrm{m}$ diameter takes place as the sample proceeds through the PM-10 inlet. The flow splitter separates the total flow $(16.71 / \mathrm{min})$ into two parts: a main flow of $31 / \mathrm{min}$ that enters the sensor unit through the sample tube, and the bypass flow of $13.7 \mathrm{l} / \mathrm{min}$. The main flow passes through the exchangeable filter in the mass transducer, and then proceeds through an air tube and in-line filter to a mass flow controller. The bypass flow is filtered in the bypass fine particulate filter and again in an in-line filter before it enters a second mass flow controller. A single pump provides the vacuum necessary to draw the sample stream through the system.

The weighing principle used in the TEOM mass transducer is fundamentally different from that on which most other weighing devices are based. The tapered element at the heart of the mass detection system is a hollow tube, clamped on one end and frees to vibrate at the other. An exchangeable filter cartridge is placed over the tip of the free end. The sample stream is drawn through this filter, and then down the tapered element. This flow is maintained at a constant volume by a mass flow controller that is corrected for local temperature and barometric pressure. The tapered element vibrates precisely at its natural frequency, much like the tine of a tuning fork. An electronic control circuit senses this vibration and, through positive feedback, adds sufficient energy to the system to overcome losses. An automatic gain control circuit maintains the vibration at constant amplitude. A precision electronic counter measures the frequency with a 1.68 second sampling period. The tapered element is in essence a hollow cantilever beam with an associated spring rate 
and mass. As in any spring-mass system, if additional mass is added the frequency readout on the screen of the computer.

\section{Non standard Remote Sensing Monitoring}

Some detectors measure the optical properties of the gas, and have been designed so that the reflected or transmitted signal is received after an extended path-length through the air. This arrangement offers the advantages of eliminating the possibility of sample degradation during passage to and through an instrument, and of integrating the concentration over a region of space rather than sampling at one point.

Remote sensing devices offer a number of advantages over competing technologies such as electro-chemical sensors or closed path optical systems, including flexibility of deployment, and avoidance of extractive sampling. The value of ROMT instrumentation has already been proven in applications including transport, power generation, chemical processing and air quality monitoring, to monitor gaseous emissions for the protection of the environment, or the safety of citizens. However the use of these instruments for formal monitoring purposes, e.g. to comply with the requirements of European directives on air quality, is hampered by the lack of instrument performance standards against which products could be certified. Remote or open-path optical systems are explicitly excluded from current gas sensing and environmental monitoring standards. This is partly owing to the difficulties in defining performance requirements which take into account the environmental factors which affect the instruments use in the field.

Remote sensing systems are now often used for detection of airborne pollutants. These systems deliver information about the concentrations in a certain region which is covered from a light beam between emitter and receiver. This results in an average value which represents mostly better the pollution level in a particular area then a point measurement. In addition they can be used for "fence-line" monitoring at industrial sites. The path length can vary from some $\mathrm{cm}$ to some hundreds of meters. The measurement can be done in the atmosphere in the so called "open-path" mode, or in a gas cell (White cell) in the so called "extractive" mode. The methodology is based on the analyses of the spectra of a light beam which passes through the ambient air (open-path) or through the White-cell (extractive). The relationship between the absorbed amount of light and the number of molecules is described by the Beer-Lambert absorption law. Due to the fact that each gas has its own typical absorption profile (finger print), it is possible to detect the concentrations of multiple gases in the same light beam either simultaneously, or one after the other.

\subsection{LIDAR}

In addition to the point measurements, the author propose to investigate air quality and specific thermodynamic and meteorological parameters, on line, by one simultaneous use of LIDAR (Light Detection and Ranging) systems, as presented by Fig. 12 (Vetres et al., 2010). 


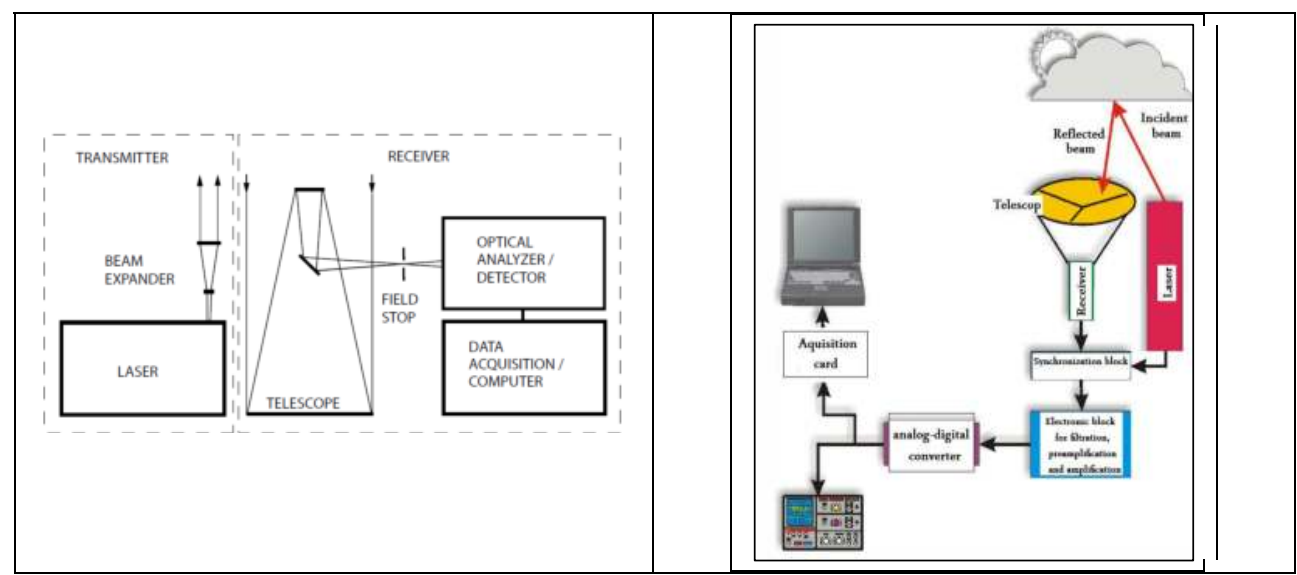

Fig. 12. Principles of functioning for LIDAR systems (Vetres, 2009).

LIDAR effectively detects and characterizes air contaminants, with best spatial and temporal resolution, locates the pollution sources and take correct actions to correct the problems while also helping in developing perspective strategies. Complementary, by applying a trajectory model or different dispersion models, one can characterize, at regional scale, the pollution regime, as well as the dynamics of the pollutants. The most obvious use is to track the evolution of a pollutant over time. Urban monitoring might be thus completed by on line LIDAR measurements, in a very modern way, in accordance to recent technical developments worldwide. Other relevant results might be analyzed from LIDAR systems are well suited for the remote measurement of pollutants, with numerous applications depending on the purpose. The most obvious use is to track the evolution of a pollutant over time. If the LIDAR laser beam is oriented vertically, the device acts as a profiler. If one changes the vertical angle of the laser beam a succession of alignments is generated that, with the proper interpolation, can define a concentration plane. The profiler is the usual configuration of the LIDAR systems, providing very valuable information, such as the depth of the planetary boundary layer and the evolution of the concentration.

Light detection and ranging (LIDAR) describes a family of active remote sensing methods. The most basic technique is long-path absorption, in which a beam of laser light is reflected from a distant retro reflector and returned to a detector which is co-located with the source. The wavelength of the radiation is chosen so that it coincides with an absorption line of the gas of interest. The concentration of that gas is found by applying the Beer-Lambert law to the reduction in beam flux density over the path length. No information is obtained on the variation in density of the gas along the path length; if the gas is present at twice the average concentration along half the path, and zero along the other half, then the same signal will be received as for uniform distribution at the average concentration.

The scheme in Fig. 13 represents the configuration of the LIDAR from the Timisoara location, as designed in order to realize analysis for the western part of Romania. 


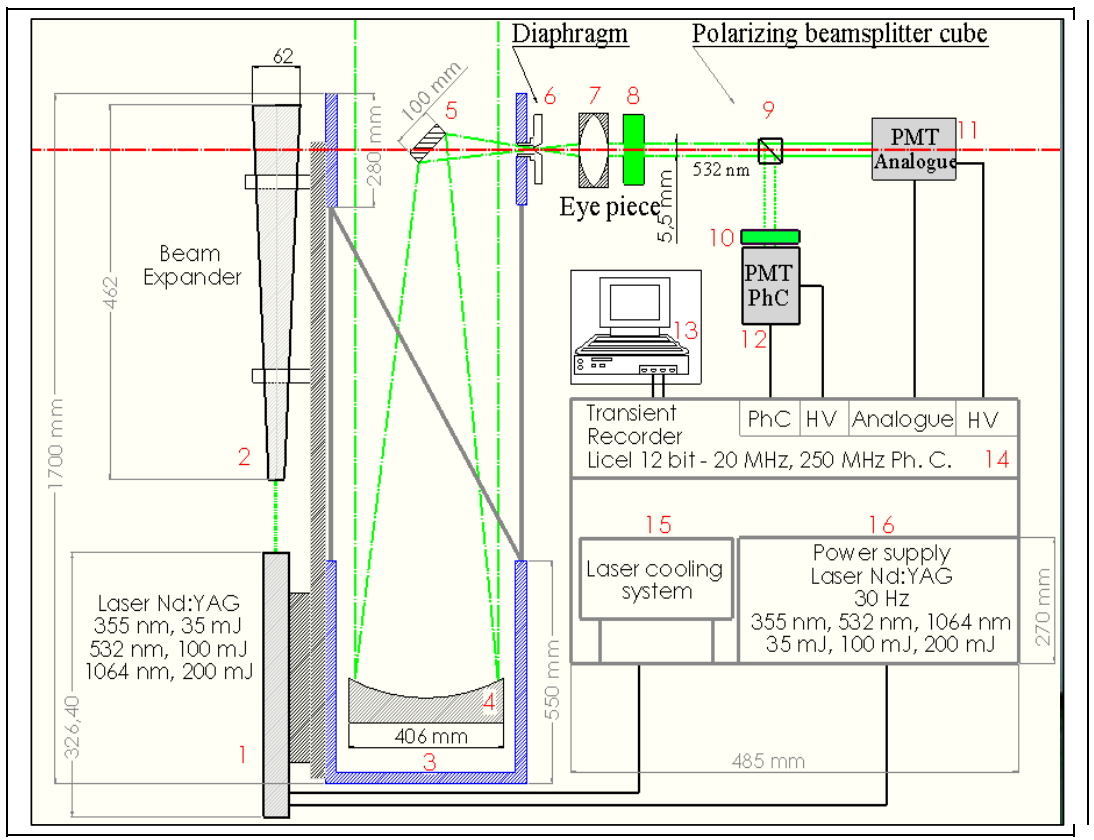

Fig. 13. Scheme of the LIDAR system (Vetres et al., 2009), (Vetres et al., 2009)

The system that has been developed is configured by following components:

Nd:YAG $30 \mathrm{~Hz}$ pulsed laser $(35 \mathrm{~mJ}$ at $355 \mathrm{~nm}, 100 \mathrm{~mJ}$ at $532 \mathrm{~nm}, 200 \mathrm{~mJ}$ at $1064 \mathrm{~nm})$;

- $\quad$ Newtonian telescope of $406 \mathrm{~mm}$ in diameter of primary mirror;

- $\quad$ Licel transient recorder acquisition cards;

- $\quad$ Analogue photo detector and Photon counting photo detector.

The acquisition for the Lidar system is based on 2 channels, $532 \mathrm{~nm}$ analogue and photoncounting (depolarization). The Licel transient recorder is a TR 20 model, with a $7.5 \mathrm{~m}$ spatial resolution. Because of the powerful $30 \mathrm{~Hz}$ YAG laser, the instrument is proper to be used in air scattering applications, the acquisition being triggered by the laser and it can record up to 30 profiles every second.

\subsection{Differential Absorption LIDAR (DIAL)}

Pulses from a tunable laser are directed into the air at two wavelengths, and the backscattered signals from the air molecules, gas molecules and particles are measured by a cooled detector. One laser wavelength ( $\mathrm{min}$ ) is just to one side of an absorption band for the gas of interest, and calibrates the backscatter of the LIDAR system for molecular (Rayleigh) and aerosol (Mie) scattering that occurs whether the gas of interest is present or not. The second laser wavelength (max) is tuned to an absorption band, so that the difference between the two can be used to derive absorption due to the gas alone. The ratio of the scattered flux density at the two wavelengths is given by (Popescu et al., 2009): 


$$
\frac{I\left(\lambda_{\max }\right)}{I\left(\lambda_{\min }\right)}=\exp (-2 R N \sigma)
$$

where $\sigma$ is the absorption cross section of the target species at wavelength $\lambda_{\max }, R$ is the range and $N$ is the number concentration of the gas.

\begin{tabular}{|l|l|l|}
\hline Molecule & $\begin{array}{l}\text { Peak absorption } \\
\text { [wavelength/nm] }\end{array}$ & $\begin{array}{l}\text { Absorption } \\
\text { [cross section } / 10-22 \mathrm{~m}^{2} \text { ] }\end{array}$ \\
\hline Nitric oxide & $226.8 ; 253.6 ; 289.4$ & $4.6 ; 11.3 ; 1.5$ \\
\hline Benzene & 250.0 & 1.3 \\
\hline Mercury & 253.7 & 56000 \\
\hline Sulphur dioxide & 300.0 & 1.3 \\
\hline Chloride & 330.0 & 0.26 \\
\hline Nitrogen dioxide & 448.1 & 0.69 \\
\hline
\end{tabular}

Table 1. Absorption wavelengths and cross sections for dye lasers.

By measuring the time for the back-scattered signal to return, the range can also be determined to within a few meters over a distance of $2000 \mathrm{~m}$. The technique has been used for studying plume dispersion and vertical concentration profiles, as well as spatial distribution in the horizontal plane. The most widely used sources are $\mathrm{CO}_{2}$ lasers emitting in the 9.2-12.6 $\mathrm{m}$ band, within which they can be tuned to emit about 80 spectral lines. For example, $\mathrm{O}_{3}$ absorbs strongly at $9.505 \mathrm{~m}$, and $\mathrm{NH}_{3}$ at $10.333 \mathrm{~m}$. In the UV-visible, dye lasers pumped by flash lamps or by laser diodes are used. By using different dyes, they are tunable over the whole visible band. Some examples of the wavelengths used are given in Table 1 (Popescu et al., 2009).

\subsection{Differential optical absorption spectroscopy (DOAS)}

The instrument consists in a detector at one end of an atmospheric path (typically 200-10 $000 \mathrm{~m}$ in length) scans across the waveband of a UV/visible source, such as a high-pressure xenon arc lamp that has a known broad spectrum, at the other end. The physical arrangement can be bi-static (with the receiver at one end and the transmitter at the other) or monostatic (a retro reflector returns the beam to the receiver, which is co-located with the transmitter). Gases that are present on the optical path absorb radiation according to the Beer-Lambert Law, and the absorption varies differently with wavelength for each gas. Variations across the spectrum are compared to stored reference spectra for different gases, and the equivalent amounts and proportions of the gases adjusted in software until the best match is achieved (Popescu et al., (2009). The main wavelength range used is $250-290 \mathrm{~nm}$, in the UV, with typical spectral resolution of $0.04 \mathrm{~nm}$. Several different gases can be measured simultaneously. Sensitivity is high, and $0.01 \%$ absorption can be detected, equivalent to subppb concentrations of many gases over a path length of $1 \mathrm{~km}$. Detectable gases include $\mathrm{SO}_{2}$, $\mathrm{NO}, \mathrm{NO}_{2}, \mathrm{O}_{3}, \mathrm{CO}_{2}, \mathrm{HCl}, \mathrm{HF}, \mathrm{NH}_{3}, \mathrm{Cl}_{2}, \mathrm{HNO}_{2}$ and many organic compounds (aldehydes, phenol, benzene, toluene, xylenes, styrene and cresol). The method is appropriate for obtaining the average concentrations of a pollutant across an urban area or along the length of an industrial plant boundary. 


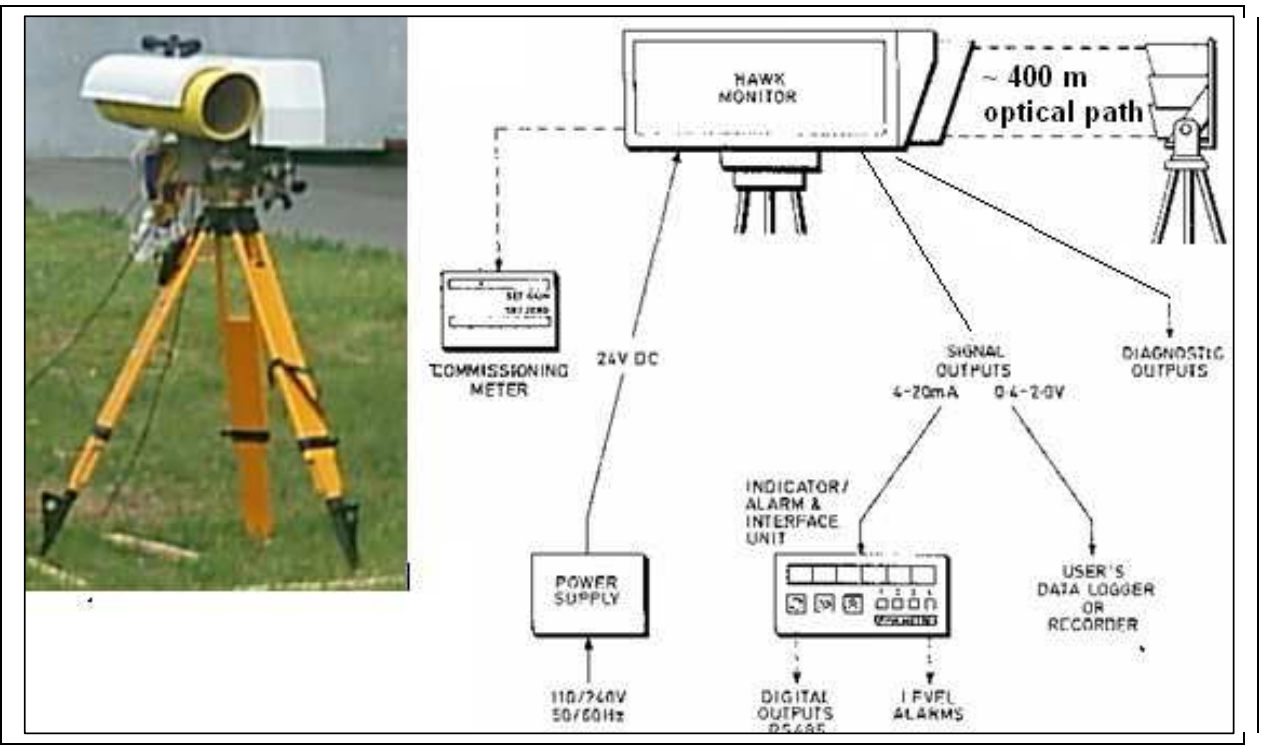

Fig. 14. Schematic of the HAWK flow diagram (Siemens Hawk Technical Manual).

An example of one DOAS instrument is given in Fig. 14. The Siemens HAWK instrument is used to measure the $\mathrm{CO}$ concentration over a 400 meters length optical path, in an intersection with intense road traffic. In addition one reference NDIR (Non - disperse Infrared) cross-flow Horiba APMA350 instrument is used to validate the DOAS measurements.

\subsection{Fourier transform infrared (FTIR) absorption spectroscopy}

This is the most optically sophisticated remote sensing technique, using a scanning Michelson interferometer to detect the entire spectral region at once, and therefore capable of measuring many gases simultaneously. The wavebands used are within the atmospheric absorption windows of $8.3-13.3$ or $3.3-4.2 \mathrm{~m}$. However, sensitivity is generally limited to a few tens or hundreds of ppb (depending on the gas) over a $200 \mathrm{~m}$ path length; the technique is therefore more appropriate to perimeter monitoring for gas escapes from an industrial site than to general ambient monitoring (Popescu et al., 2009).

Infrared spectroscopy has been used for several decades, initially developed for the detection of atmospheric $\mathrm{CO} 2$ by non-dispersive instruments. Instruments based on Fourier transform spectroscopy can measure a lot of species by means of multiple reflection cells (White cells) as well as in open-path mode, and has been improved during the last years from a laboratory instrument to an instrument for in-situ emission and/or air quality measurements.

All polyaromatic molecules and heteronuclear diatomic molecules absorb infrared radiation. The absorption changes the molecular rotation and vibration. The pattern of absorption therefore depends on the physical properties of the molecule such as the number and type of atoms, the bond angles, and the bond strengths. This means that each spectrum differs from all others and may be considered the molecular "signature" (finger-print). Monatomic gases such as radon and homonuclear diatomic molecules such as $\mathrm{N}_{2}$ and $\mathrm{O}_{2}$ do not have infrared bands and therefore must be measured with non-infrared means. Diatomic molecules such a 
$\mathrm{NO}, \mathrm{CO}, \mathrm{HCl}$, and $\mathrm{HF}$ have a single major band that is an array of individual lines, each with a width of about $0.2 \mathrm{~cm}^{-1}$. Linear polyatomic molecules like $\mathrm{CO}_{2}, \mathrm{~N}_{2} \mathrm{O}$, and $\mathrm{C}_{2} \mathrm{H}_{2}$ also show arrays of individual lines. Non-linear polyatomic molecules like $\mathrm{O}_{3}, \mathrm{SO} 2, \mathrm{NH}_{3}, \mathrm{H}_{2} \mathrm{CO}$, $\mathrm{CH}_{4}$, and $\mathrm{H}_{2} \mathrm{O}$ have many apparent "lines" that is in fact small bundles of lines, with the widths of the bundles varying from $0.2 \mathrm{~cm}^{-1}$ to many $\mathrm{cm}^{-1}$. For larger polyatomic molecules at atmospheric pressure there are so many lines overlapping each other that the spectral features are broad and smooth, except for occasional "spikes" (Nicolae \& Cristescu, 2006).

The big advantage of "open-path" measurements can be found in the detection of emissions from diffusive sources, e.g. a lot of small sources in industrial plants, waste deposits, waste water facilities, or at fence-line monitoring, where a possible pollution transport over particular boundaries has to be monitored, e.g. prevention of losses of hazardous pollutants.

\section{Examples and Comments of Air Quality Monitoring Results}

The examples that are following are given in the idea to complete the theoretical information from previous, and to give realistic data concerning on line monitoring campaigns. Two main episodes were selected, referring to two locations: (i) an airport), and (ii) urban area. Also for the first episode parallel measurements have been recorded, by two independent laboratories (http://inoe.inoe.ro/RADO).

Following pollutants have been continuously measured, with $10 \mathrm{sec}$ resolution, over the entire measuring episode with high precision equipment (Ionel et al., 2008):

- $\quad \mathrm{SO}_{2}$ measured with two Horiba APSA370 instruments, measurement principle is UV fluorescence, reference method: EN 14212:2005. The combined measurement uncertainty is $U=1.76 \%$ for recorded values;

- $\quad \mathrm{NO}, \mathrm{NO}_{2}$ and $\mathbf{N O}_{\mathbf{x}}$ measured with two Horiba APNA370 instruments, measurement principle is chemiluminescences, reference method: EN 14211:2005. The combined measurement uncertainty is $U=2.06 \%$ for recorded values;

- $\mathrm{O}_{3}$ measured with two Horiba APOA370 instruments, measurement principle is UV photometry, reference method: EN 14625:2005. The combined measurement uncertainty is $U=6.98 \%$ for recorded values;

- $\quad$ CO measured with two Horiba APMA370 instruments, measurement principle is NDIR (Non Dispersive Infrared), reference method EN 14626:2005. The combined measurement uncertainty is $U=4 \%$ for recorded values;

- $\quad \mathbf{C H}_{4}, \mathbf{N M H C}$ and THC measured with two Horiba APHA370 instruments, measurement principle is FID (flame ionization detection), reference method EN 12619:2002. The combined measurement uncertainty is $U=0.9 \%$ for recorded values;

- $\quad$ Other gases have been measured with DOAS Instruments 


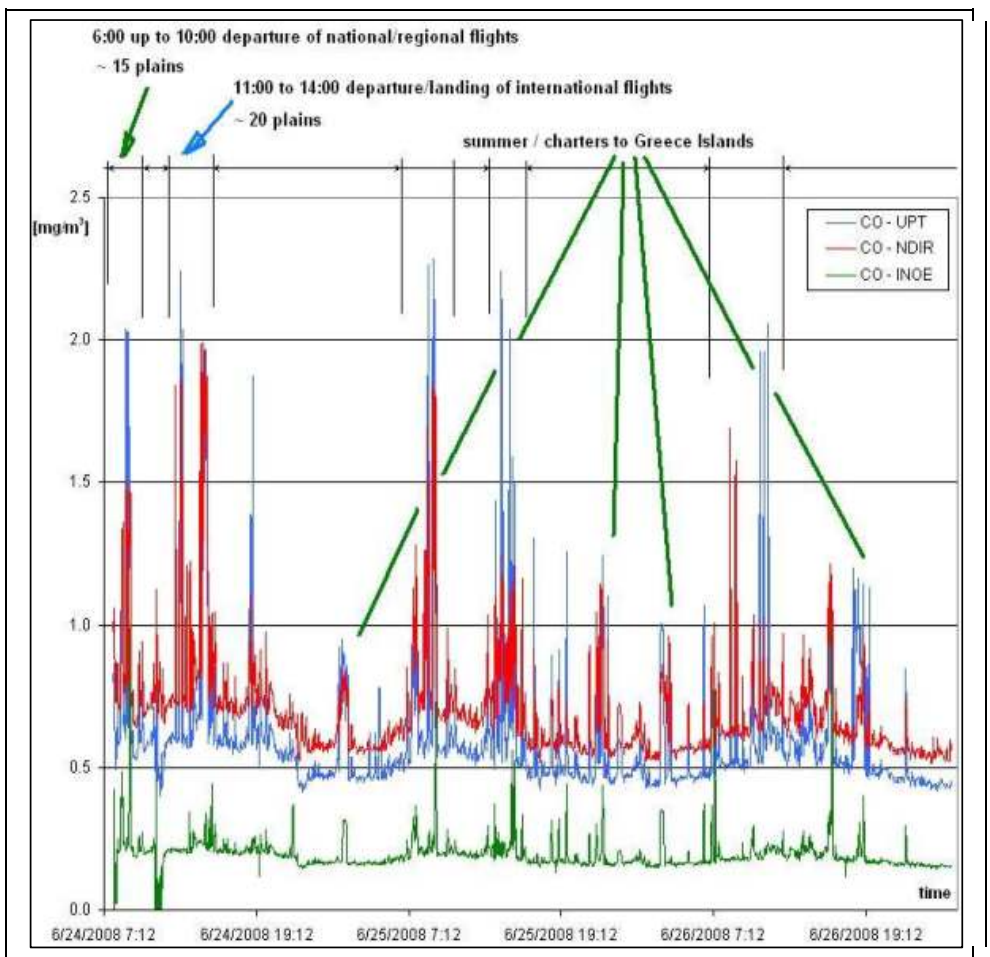

Fig. 15. CO measurements and airplanes traffic.

Fig. 15 shows the carbon monoxide $\mathrm{CO}$ recorded values, measured with 3 different instruments: two reference NDIR point measurement instruments and one DOAS-IR Siemens-Hawk instrument.

The different methods used for CO measurements have given same result; the high concentration recorded values and background concentration values are similar for point and open path instruments. The CO-INOE measurements are in the same trend but the measured values are with $\sim 0.4 \mathrm{mg} / \mathrm{m}^{3} \mathrm{~N}$ lower than the other instruments. This could be caused by an error in span gas calibration. On top of the figure 2 are drafted the departures and arrivals of national/regional, international and charters corroborated with the carbon monoxide measured values. The dependency between aircraft traffic on the apron and the $\mathrm{CO}$ measured values is visible in figure 2 , the higher values for $\mathrm{CO}$ have only been recorded during the departure or landing of the aircrafts. This result is important because it demonstrates that the selected placement of the mobile air laboratories near the airport facilities and apron is ideal for depicting the air quality and the measured values can be considered representatives for the airport facilities surroundings.

The measured values for carbon monoxide are much lower than the $10 \mathrm{mg} / \mathrm{m}^{3}$ limit value, regulated by 2000/69/EC Directive. The measured values were normal because the airport location is far-off from the city or any main road and the only CO source is represented by the aircrafts.

Fig. 16 shows the mean measured values of sulfur dioxide $\mathrm{SO}_{2}$, measured by two instruments. 


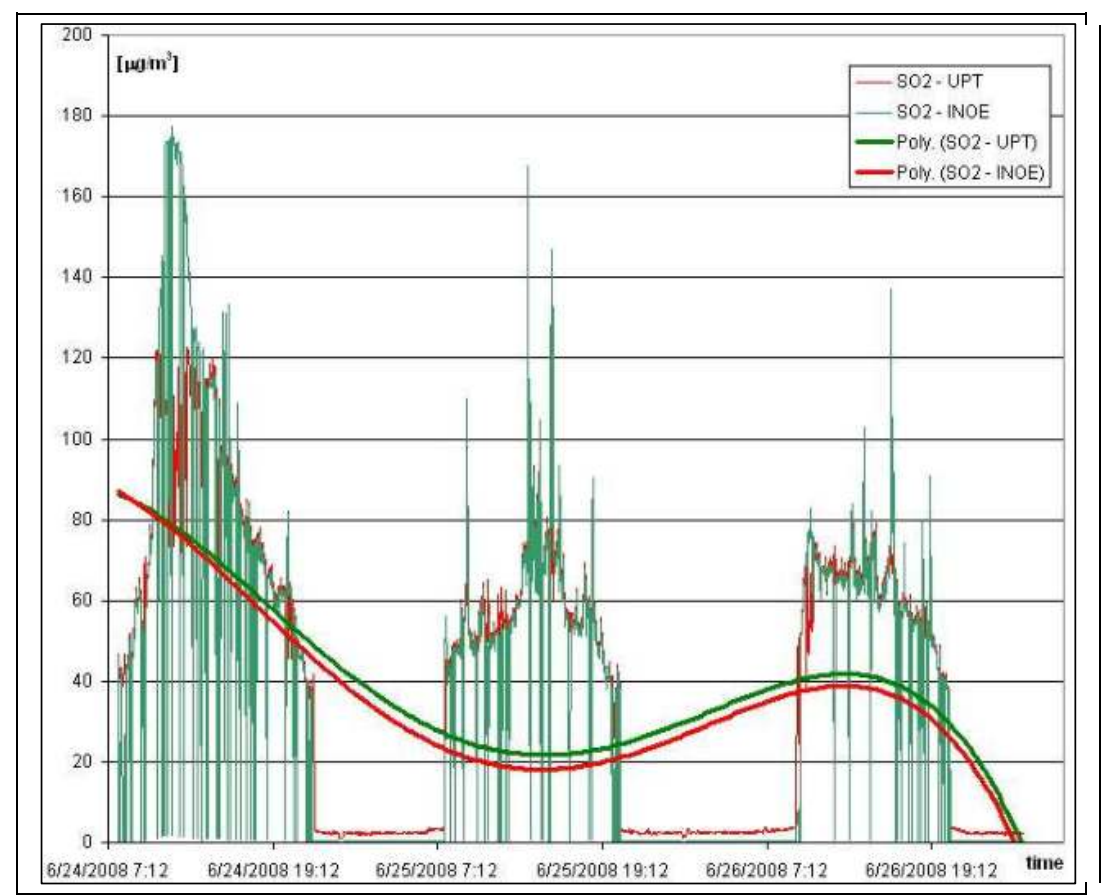

Fig. 16. $\mathrm{SO}_{2}$ measurements and polynomial (4 degree) trend lines.

The $\mathrm{SO}_{2}$ concentration in air is continuously measured and recorded (one value every second) and mediated every 3 minutes. Because the $\mathrm{SO}_{2}$ - INOE instrument has given high variations (in short term intervals) two $4^{\text {th }}$ degrees polynomial trend lines are added to the graph, one for the recorded values of each instrument. The correlation between the instruments is acceptable, just differences of about $5 \mu \mathrm{g} / \mathrm{m}^{3} \mathrm{~N}$ are recorded, differences that can be considered equivalent within the measurement uncertainty.

The recorded values for $\mathrm{SO}_{2}$ are not higher then the $350 \mu \mathrm{g} / \mathrm{m}^{3} \mathrm{~N}$ limit value regulated by 1999/30/EC Directive but they are about 10 times higher then the background values (7 $\mu \mathrm{g} / \mathrm{m}^{3} \mathrm{~N}$ ). The 3 minutes mean value have been used for an easy observation of the influence of airplanes traffic on pollutants concentration, that is the main purpose of this study. The $\mathrm{SO}_{2}$ concentrations below $150 \mu \mathrm{g} / \mathrm{m}^{3}$ have only moderate (and reversible) irritant effect on human respiratory system, but in synergy with $\mathrm{NO}_{x}$ and high air humidity can cause permanent pulmonary impairment (according to CCOHS - Canadian Centre for Occupational Health and Safety). The only possible source responsible for the $\mathrm{SO}_{2}$ high values is the airplane fuel because there are no other possible emission sources of $\mathrm{SO}_{2}$ in the airport vicinity (no main road traffic or industrial areas). The ground support vehicles are limited in number ( 5 busses and 2 passenger cars) and their contribution to airport emissions is insignificant (Ionel et al., 2010). 


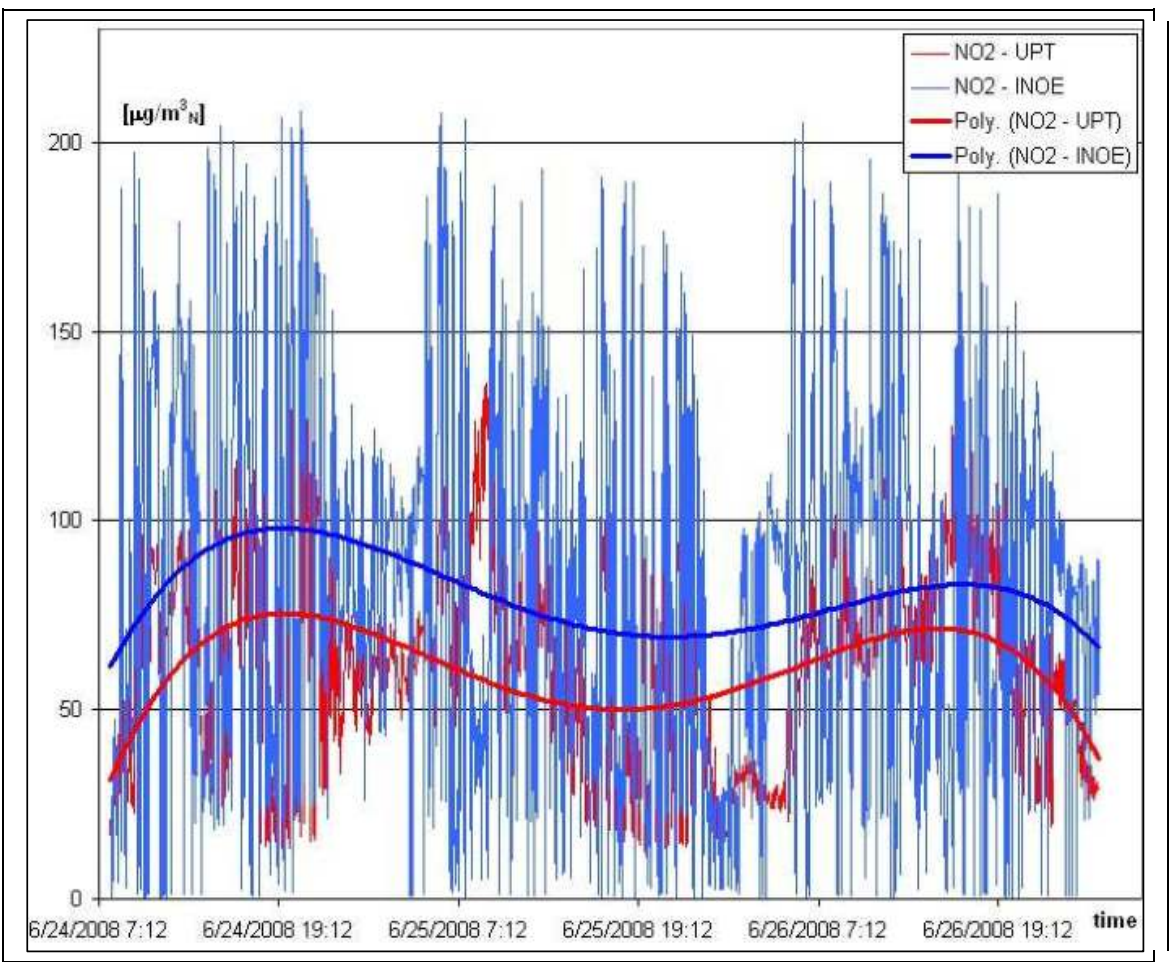

Fig. 17. $\mathrm{NO}_{2}$ measurements and polynomial (4 degree) trend lines.

Fig. 17 shows the measured values for nitrogen dioxide $\mathrm{NO}_{2}$, with two identical instruments. The correlation between the instruments is good, polynomial trend lines have been added for better resolution. The recorded values are similar for both instruments and higher then the $200 \mu \mathrm{g} / \mathrm{m}^{3}{ }_{\mathrm{N}}$ limit value regulated by $1999 / 30 /$ EC Directive. Because the highest measured values is overlapping airplane traffic on apron it is clear that the only possibility to reduce $\mathrm{NO}_{2}$ concentration is to manage more efficient airplane taxiing procedures.

Figure 18 shows the measured values for methane $\mathrm{CH}_{4}$, non-methane hydrocarbon NMHC (VOC) and total hydrocarbon THC, with one FID (flame ionization detection) instrument. The recorded values for methane are higher that the global background (1.7 ppm) with only $0.4 \mathrm{ppm}$. The values recorded for volatile organic compounds are up to $3 \mathrm{mg} / \mathrm{m}^{3} \mathrm{~N}$ in periods with high airplane traffic. These values are representing a serious concern for the passenger health, knowing that some on these volatile compounds (like benzene) are causing cancer (www.epa.gov/). VOCs include a variety of chemicals, some of which may have short- and long-term adverse health effects. Key signs or symptoms associated with exposure to VOCs include conjunctival irritation, nose and throat discomfort, headache, allergic skin reaction, dyspnea, declines in serum cholinesterase levels, nausea, emesis, epistaxis, fatigue, dizziness. As with other pollutants, the extent and nature of the health effect will depend on many factors including level of exposure and length of time exposed. The measured values for VOCs are up to $3 \mathrm{mg} / \mathrm{m}^{3}\left(3000 \mu \mathrm{g} / \mathrm{m}^{3}\right)$. These values emerge not only during airplanes departure or arrivals, but mostly when the airplanes are fueled. 


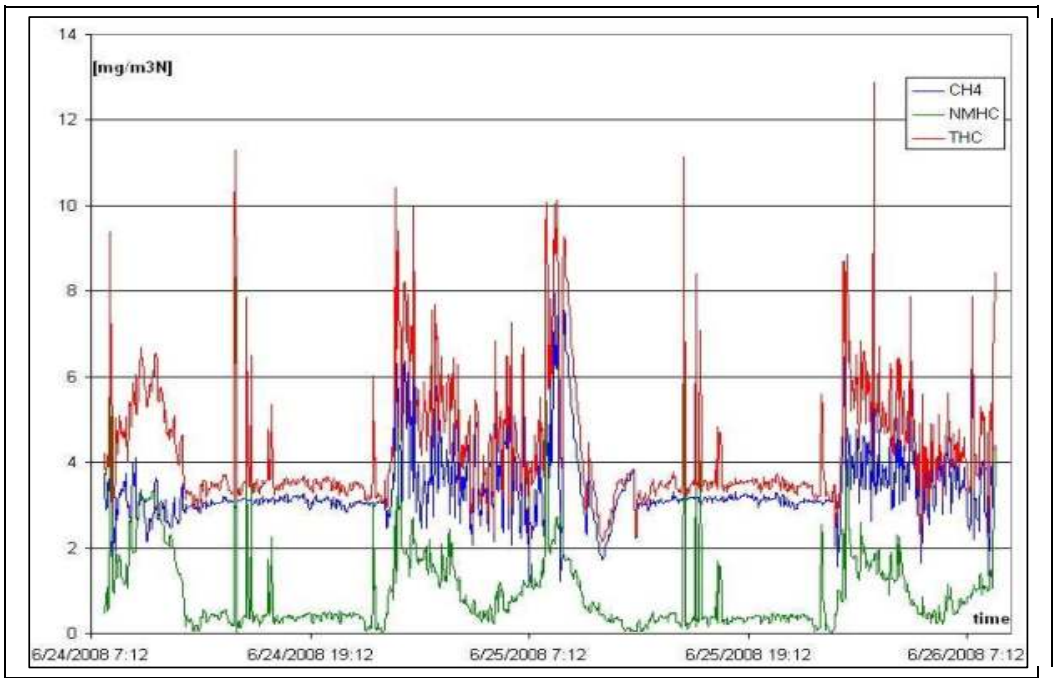

Fig. 18. $\mathrm{CH}_{4}, \mathrm{NMHC}$ (VOC) and THC measurements, 3 minutes mean value.

The most relevant values recorded with INOE DOAS instrument are presented in figures 19 to 22. Very high values have been recorded for acrolein and tert-butil. Also significant values were recorded for benzen, toluen, benzaldehyde, O-cresol, O-xylen, (2, 5) - dimethyl, and also for P-tolylaldehyde.

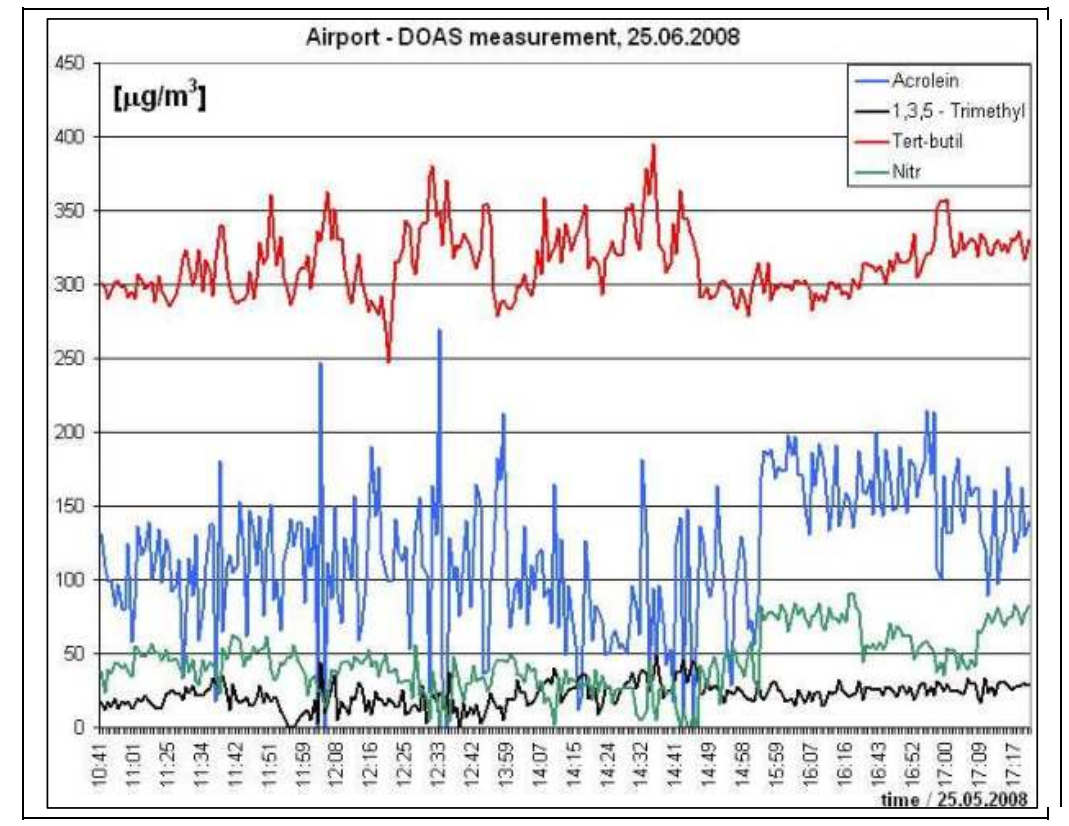

Fig. 19. DOAS measurements. Several species for the episode 25.06.2008, 3 minutes mean value. 


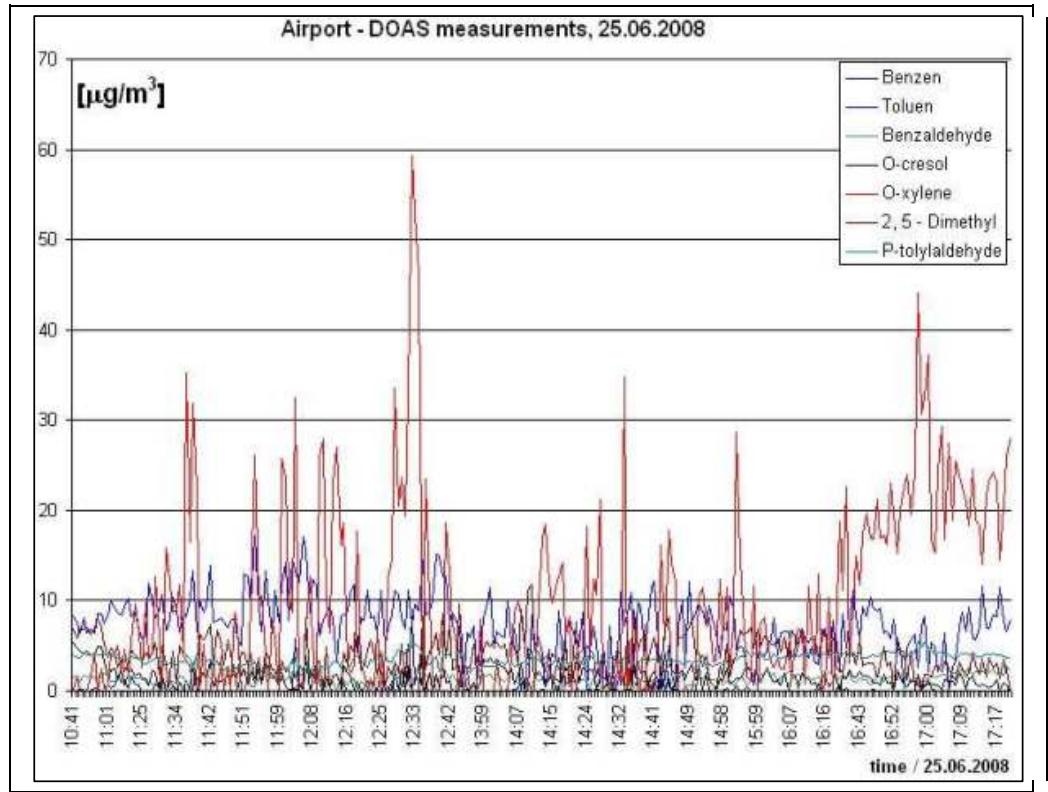

Fig. 20. DOAS measurements of several species for the episode $25.06 .2008,3$ minutes mean value.

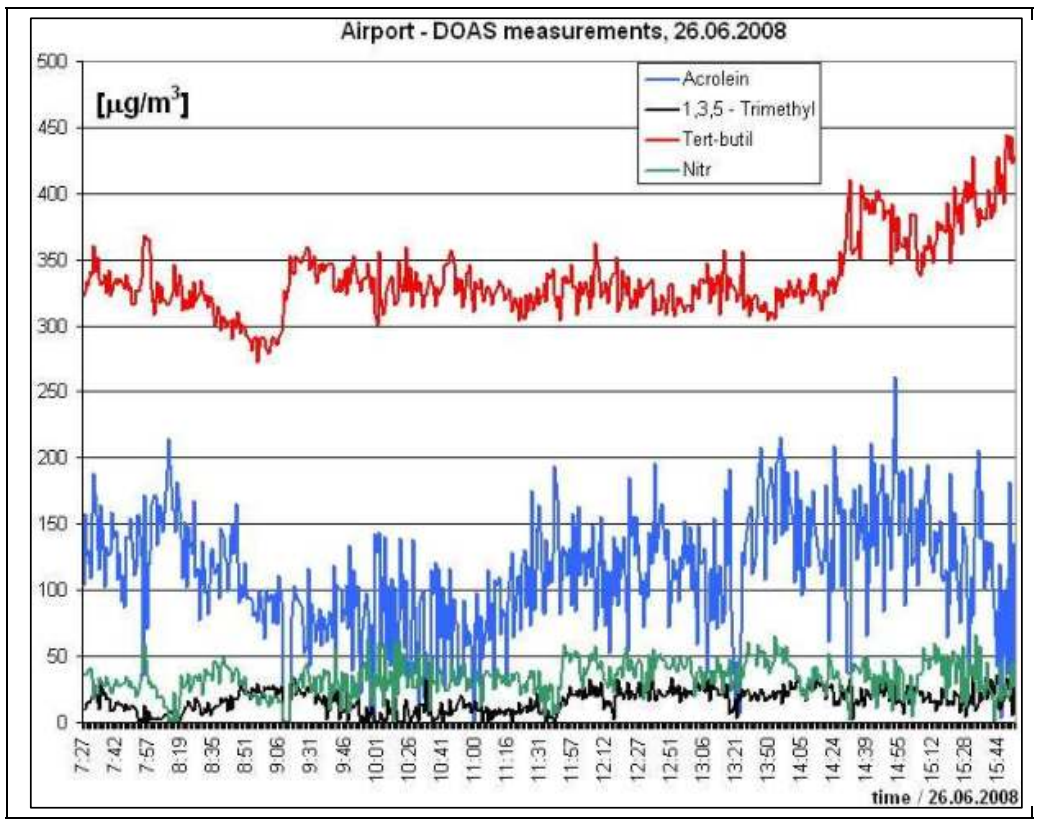

Fig. 21. DOAS measurements of several species for the episode $26.06 .2008,3$ minutes mean value. 


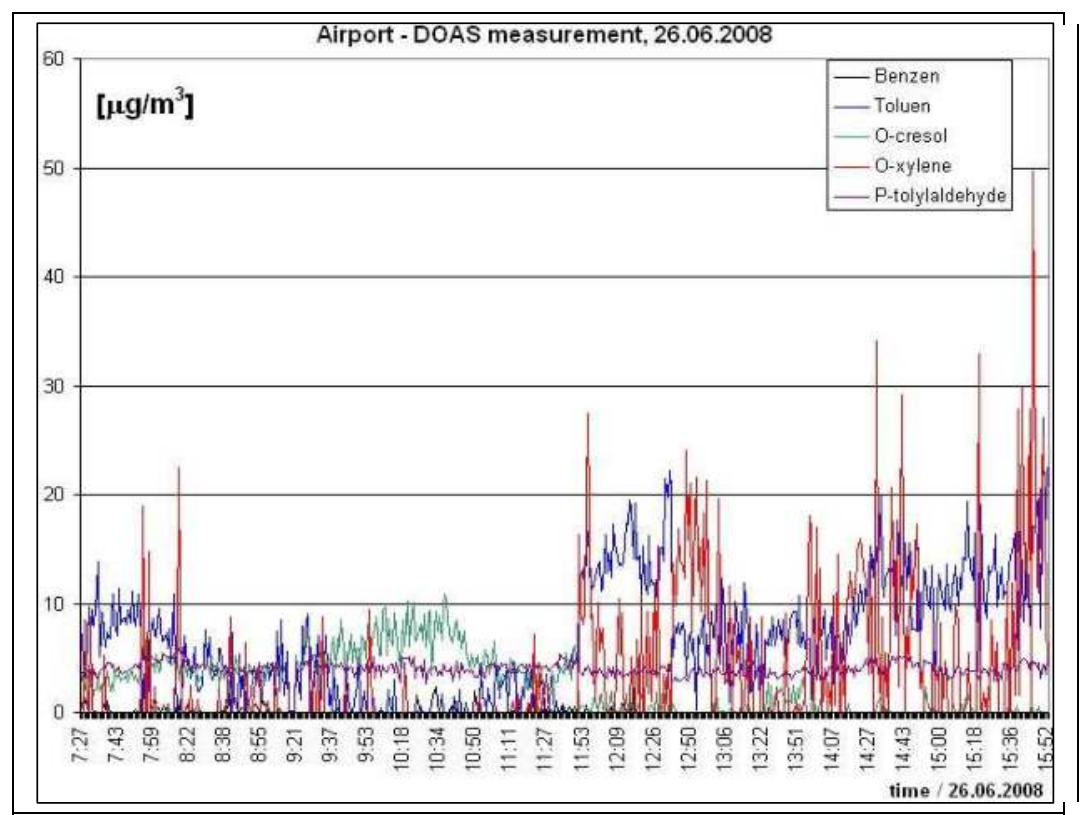

Fig. 22. DOAS measurements of several species during 26.06.2008, 3 minutes mean value.

It is well known that acrolein may be released to the environment in emissions and effluents from its manufacturing and use facilities, in emissions from combustion processes (including cigarette smoking and combustion of petrochemical fuels), from direct application to water and waste water as a slimicide and aquatic herbicide, as a photooxidation product of various hydrocarbon pollutants found in air (including propylene and 1,3-butadiene), and from land disposal of some organic waste materials. Acrolein is a reactive compound and is unstable in the environment (Popescu, 2009). In ambient air, the primary removal mechanism for acrolein is predicted to be reaction with photochemically generated hydroxyl radicals (half-life, 15-20 hours). Products of this reaction include carbon monoxide, formaldehyde, and glycolaldehyde. In the presence of nitrogen oxides, eroxynitrate and nitric acid are also formed. Small amounts of acrolein may also be removed from the atmosphere in precipitation. Insufficient data are available to predict the fate of acrolein in indoor air (Nicolae et al., 2007). But experimental data indicate that reaction of acrolein with ozone in specific conditions $\left(\mathrm{k}=2.8 \times 10^{-19} \mathrm{~cm}^{3} /\right.$ molecules-sec at $25^{\circ} \mathrm{C}$; half-life, 59 days) or nitrate radicals $\left(\mathrm{k}=5.9 \pm 2.8 \times 10^{-16} \mathrm{~cm}^{3} /\right.$ molecules-sec at $25^{\circ} \mathrm{C}$; half-life, 16 days) in the troposphere would be too slow to be environmentally significant (Nicolae \& Cristescu, 2006), (Wang et al., 2009), (Ionel et al., 2010).

The second range of examples is comparisons between urban episodes from two EU cities, one in Romania (Timisoara - TM), one in Austria (Graz - GdB).

When considering carbon monoxide $(\mathrm{C} 0)$ the maximum hourly mean value shows differences in the order of five to ten (Fig. 23). As Graz don Bosco is already the traffic hot spot of Graz the main reason of this difference can only be found in the difference of the technical standards of the vehicle fleet. The Austrian vehicle fleet consists of gasoline vehicles with three way catalytic converters and of diesel cars. Both groups have very small 
CO concentrations. This is not the case for the vehicle fleet of Timisoara. Cars and domestic heating contribute strongly to the high $\mathrm{CO}$ level.

Figure 24 depicts the $\mathrm{NO}, \mathrm{NO}_{2}$ and $\mathrm{SO}_{2}$ concentrations; again the maximum hourly value is shown. $\mathrm{NO}$ and $\mathrm{NO}_{2}$ are in most - but not all - cases in Timisoara higher than in Graz don Bosco. A clear picture is given only for $\mathrm{SO}_{2}$ - which is a tracer for emissions from industry and private households. In Graz there is almost no $\mathrm{SO}_{2}$ concentration measured, whereas Timisoara shows levels up to $50 \mu \mathrm{g} / \mathrm{m}^{3}$, but well below the threshold of $200 \mu \mathrm{g} / \mathrm{m}^{3}$.

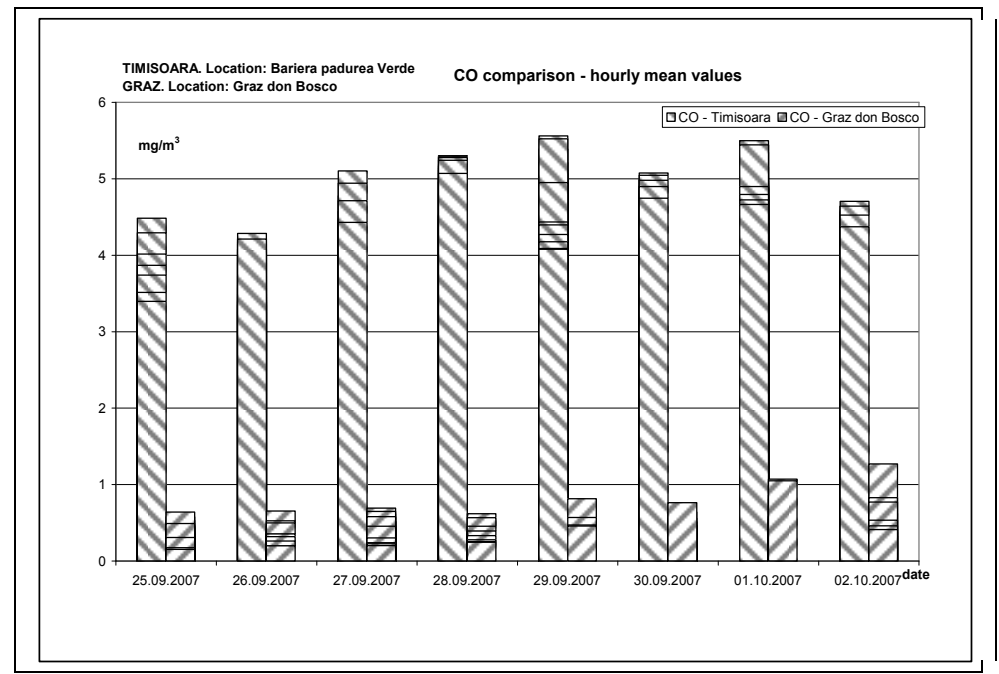

Fig. 23. Comparative CO one hour mean values.

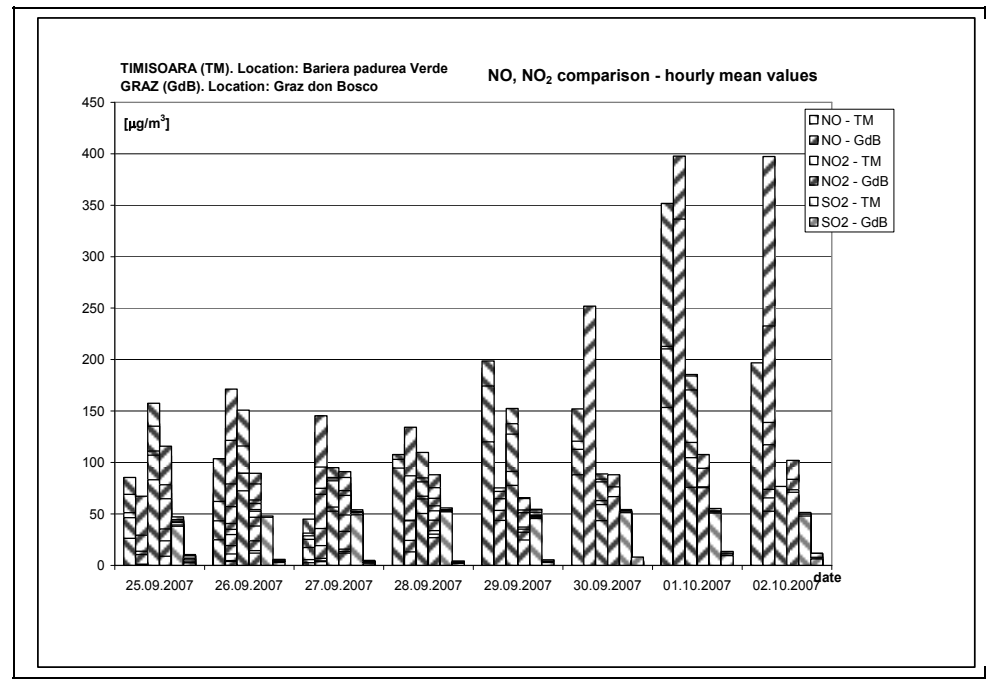

Fig. 24. Comparative $\mathrm{NO}, \mathrm{NO}_{2}, \mathrm{SO}_{2}$ one hour mean values. 
The comparison between AQ online monitoring data in two European cities (even no megacities) proofs that despite the fact that the same EU legislation and monitoring methods are applied, the results are quite different.

Finally new results taken by the LIDAR system of the RADO (Romanian Atmospheric 3D research Observatory Project) consortium project in Romania are presented by Fig. 25 . Thus the Range Corrected Signal from April 22-th, 2010, evening, is presented, indicating that the volcanic cloud is observed already starting from $3 \mathrm{~km}$ high, with an ascendant tendency, and that at $4.5 \mathrm{~km}$ approximately the clouds are formed. Combining LIDAR observations with in situ measurements and models is a strong complementary support for monitoring of different atmospheric parameters over various space-time scales, promoting the remotesensing approaches in environmental applications. The Romanian Atmospheric research 3D Observatory (RADO) is an ambitious facility that aims to improve modelling of physical, chemical, and biological processes, to assess the effects of climate change, and to quantify and reduce uncertainties in evaluating the hydrological cycle and its influence on natural resources. Over the last five years, environmental research has focused increasingly on remote sensing of the atmosphere. The station is able to monitor a number of atmospheric parameters, including trace gases and aerosols, as well as meteorological ones. Microwave spectroscopy and mass spectrometry are the latest techniques to be implemented at this site.

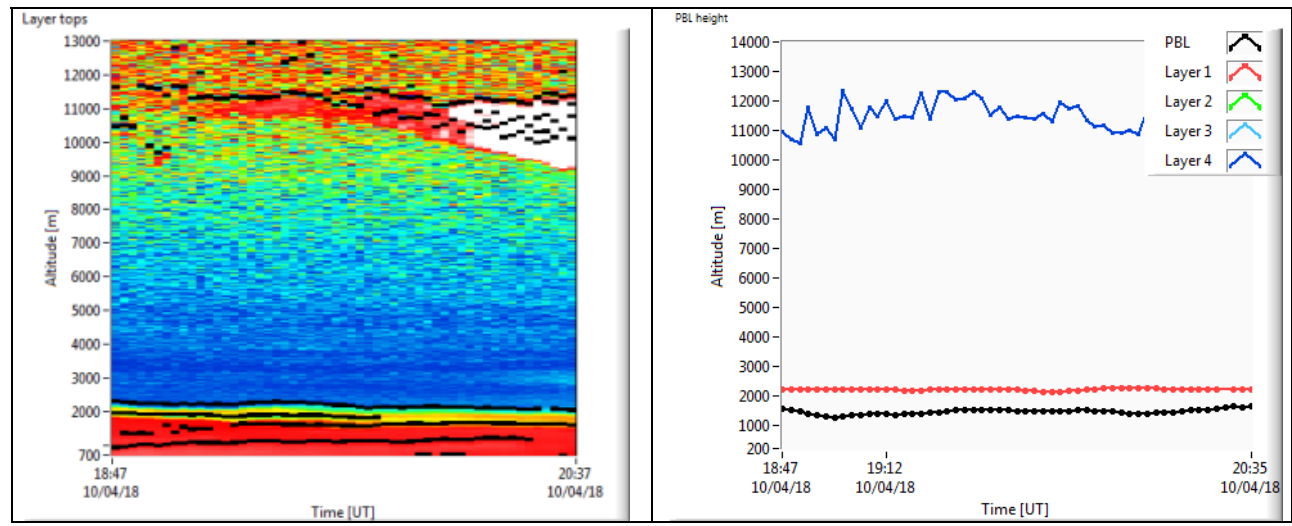

Fig. 25. Range corrected signal from April 22-th, 2010, evening, presenting the Cloud and volcanic layer formation (http://inoe.inoe.ro/RADO).

\section{Conclusion}

Air pollution is a global environmental problem that represents a measure of the potential of the climate change rate influenced by local pollution sources, although its scale has a strong regional or local orientation. Improvements in technology supported by policy measures have lead to reduced pollution levels, but still, especially in new member states, more activity is needed. In developed countries advanced low pollution technique is applied in order to reduce the pollution levels However, in developing countries the relatively high economic growth rates increase the incomes but also the global (regional or local) pollution level, and hence contribute as long range transported pollution to air quality problems in regions far away. Reaching the stringent AQ levels remains to be the challenge for all 
countries and especially for urban areas. This calls for an intensive cooperation between all cities, in developed or developing countries, in terms of research collaboration, technology transfer, knowledge exchange and dissemination.

There are many ways to measure air pollution, basic they are referring either to standard methods or to acceptable one, with both simple chemical and physical methods and with more sophisticated electronic techniques, in addition to modelling possibilities, according special tailored programs, according emission factors and pollutant inventory, for real or probable meteorological conditions (Ionel, \& Popescu, 2009), (Varga et al., 2010). Automatic methods produce high-resolution measurements of hourly pollutant concentrations or better, at a single point. Pollutants analyzed include ozone, nitrogen oxides, sulphur dioxide, carbon monoxide and particulates. The samples are analyzed using a variety of methods including spectroscopy. The sample, once analyzed is downloaded in real-time, providing very accurate information. Remote optical, long path analyzers use spectroscopic techniques, make real-time measurements of the concentrations of a range of pollutants.

\section{References}

Apascaritei, M.; Popescu, Fr. \& Ionel, I. (2009). Air pollution level in urban region of Bucharest and in rural region, SSE'09 Proceedings of the $11^{\text {th }}$ WSEAS International Conference on Sustainability in Science Engineering, pp. 330 - 335, ISBN 978-960-474080-2, Timisoara, Romania

Baumann, K. (1987). Schadstoffausbreitung im Nahbereich einer Autobahn, Institut für Verfahrenstechnik und Dampfkesselwesen der Universität Stuttgart, Abt. Reinhalt. Luft, Bericht Nr. 8

Baumbach, G.; Baumann, K. \& Dröscher, F. (1987). Luftverunreinigungen in Wäldern, Institut für Verfahrenstechnik und Dampfkesselwesen der Universität Stuttgart, Abteilung Reinhalt. Luft, Bericht Nr. 5

Birkle, M. (1979). Messtechnik für den Immissionsschutz - Messen der gas- und partikelförmigen Luftverunreinigungen. München Wien: Oldenburg

DIN 1319, (1985) Teil 1: Grundbegriffe der Messtechnik - Allgemeine Grundbegriffe. Berlin: Beuth 6

Erste allg. (1986) Verwaltungsvorschrift zum Bundes-Immissionsschutzgesetz (Technische Anleitung zur Reinhaltung der Luft - TA Luft), GMBI, S.95f

Esser, J. (1982). Schadstoffkonzentration im Nahbereich von Autobahnen in Abhängigkeit von Verkehr und Meteorologie. In: Kolloquiumsbericht "Abgasbelastungen durch den Kraftfahrzeugverkehr im Nahbereich verkehrsreicher Straßen", TÜV Rheinland und Umwelt 3/82, S. 158-164, Köln, Germany

Finlayson-Pitts, B. \& Pitts, J. (1986). Atmospheric chemistry: fundamentals and experimental techniques, John Wiley \& Sons, p.10, ISBN: 978-0471882275, University of Michigan

FVLR (1979). Institut für Reaktionskinetik: Messgerät zum Nachweis von Stickstoffoxiden. Exponatbeschreibung, Stuttgart, Germany

Hartkamp, H.; Buchholz, N.; Klukas, F. \& Münch, J. (1983). Ermittlung und Erprobung von Kalibrierverfahren für Immissionsmessnetze, Umweltforschungsplan des Bundesministers des Innern, Forschungsbericht 10402 216, UBA-FB 83 - 034, Materialien 3/83, Berlin: Erich Schmidt 
Hartmann \& Braun AG. (1982). NDUV - Betriebsphotometer Radas 1G. Gebrauchsanweisung 42/20-22-1 bzw. Listenblatt 20-1.53, Frankfurt

HORIBA GmbH Process \& Environmental, AP 370 User manuals, http://www.horiba.com/process-environmental/products/ambient/

http://www.epa.gov/iaq/schools/tfs/guidem.html, United States Environmental Protection Agency, IAQ TfS Action Kit

http://www.mediu.ro, Laboratory for Fuel Analyses, Environmental Investigations and Pollutants Dispersion

http://www.thermoscientific.com/wps/portal/ts/HOME, Thermo Scientific, User manual TEOM Monitor

http://inoe.inoe.ro/RADO/\#, Romanian Atmospheric 3D research Observatory Project

Immissionsmessnetze in der Bundesrepublik Deutschland (Stand 1987). In: Monatsberichte aus dem Messnetz 8/87, Umweltbundesamt Berlin, Germany

Ionel, I.; Nicolae, D.; Popescu, Fr.; Talianu, C.; Belegante, L. Apostol, G. (accepted paper for publication in 2010) http://www.nipne.ro/rjp/accepted_papers.htm. Measuring Air Pollutants in an International Romanian Airport with Point and Open Path Instruments, Romanian Journal of Physics, Publishing House of the Romanian Academy

Ionel, I. \& Popescu, Fr. (2009). Data acquisition system in a mobile air quality monitoring station, 5th International Symposium on Applied Computational Intelligence and Informatics, IEEE Catalog Number: CFP0945C - CDR, pp. 547-552, ISBN: 978-1-42444477-9, Timisoara, Romania

Ionel, I.; Ionel, S.; Popescu, Fr.; Padure, G.; Dungan, L. \& Bisorca, D. (2008). Method for determination of an emission factor for a surface source, Optoelectronics and Advance Materials - Rapid Communication Journal, Vol 2 (12), pp.851 - 854, ISSN 1842-6573

Ionel, I., (2000). Dispersia noxelor. Teorie si aplicații. Editura Politehnica, Timişoara, ISBN:9739389-58-9

Kaiser, R. (1965). Chromatographie in der Gasphase. Teil 4: Quantitative Auswertung. Mannheim: Bibliographisches Institut

Kost, W. \& Baumbach, G. (1985). Messung der vertikalen Konzentrationsgradienten der Spurengase $\mathrm{NO}, \mathrm{NO}_{2}, \mathrm{SO}_{2}$ und $\mathrm{O}_{3}$ in Waldbeständen im Schönbuch und Schwarzwald. VD1 Ber. 560, S. 205 -239, Düsseldorf, Germany

Laskus, L. \& Bake, D. (1976). Erfahrungen bei der Korngrößenanalyse von Luftstäuben mit dem Andersen-Kaskadenimpaktor, Staub-Reinhalt. Luft 36, Nr. 3, S. 102-106

Nicolae, D.; Talianu, C.; Carstea, E. \& Radu, C. (2007). Using classification to derive aerosol number density from lidar measurements, Journal Optoelectronics and Advanced Materials, Vol.9 (11), pp.3518-3521, ISSN 1454-4164

Nicolae, D. \& Cristescu, C., P. (2006). Laser remote sensing of tropospheric aerosol, Journal Optoelectronics and Advanced Materials, Vol. 8 (5), pp.1781-1795, ISSN 1454-4164

Paffrath, D. (1985). DFVLR - Messsystem zur Erfassung der räumlichen Verteilung von Umweltparametern in der Atmosphäre mit mobilen Messträgern. Forschungsbericht 85-09. DFVLR Institut für Physik der Atmosphäre. Oberpfaffenhofen

Popescu, Fr.; Ionel, I.; Lontis, N.; Calin, L. \& Dungan L. (accepted paper for publication in 2010) http://www.nipne.ro/rjp/accepted_papers.htm. Air Quality Monitoring in an Urban Agglomeration, Romanian Journal of Physics, Publishing House of the Romanian Academy 
Popescu, Fr. (2009). Advantages in the use of Biodiesel in an urban fleet. Case study: major cross-roads in the Timisoara city, Journal of Environmental Protection and Ecology, Vol.10 (1), pp.182-191, ISSN 1311-5065

Popescu, Fr.; Ionel, I. \& Ungureanu, C. (2009). Ambient air quality measurements in Timisoara. Current situation and perspectives, Journal of Environmental Protection and Ecology, Vol.10 (1), pp.1-13, ISSN: 1311-5065

Popescu, Fr.; Ionel, I.; Pavlovic, M. \& Pavlovic. Al. (2009). Air pollution monitoring, Proceedings of the 4th Symposium "Recycling technologies and sustainable development", Zbornik Radova Proceeding, p.451-462, ISBN: 978-86-80987-73-6, Bor, Serbia

Projektgruppe Bayern zur Erforschung der Wirkung von Umweltschadstoffen (PBWU): Atlas der Immissionsmessstationen Europas, 2. Aufl. Gesellschaft für Strahlen- und Umweltforschung, GSF-Bericht 25/87, München, Germany

RdSchr. (1983) des Bundesministers des Innern betreffend Bundeseinheitliche Praxis bei der Überwachung der Emissionen und Immissionen -UI8 - 556134/4 - , II. Richtlinien für die Wahl der Standorte und die Bauausführung automatischer Messstationen in telemetrischen Immissionsmessnetzen, GMB1. S. 76-78

Varga, L.; Apascaritei, M.; Ionel, I. \& Popescu Fr. (2010). Contribution to air quality monitoring in the eastern part of Timisoara city, Revista Metalurgia International, No.6, Editura Stiintifica F.M.R., pp.40-45, ISSN: 1582-2214

Vetres, I.; Ionel, I.; Popescu Fr.; Nicolae, D.; Talianu, C. \& Dungan, L. (accepted paper for publication in 2010). Lidar. Systems implementation and development in Timisoara urban area. Digest Journal of Nanomaterials and biostructures, Published NIMPBucharest, ISSN: 1842-3582

Vetres, I.; Ionel, I.; Padureanu, I. \& Lontis, N. (2009). Sistemul Lidar pentru investigarea aerosolului atmosferic, Revista Metalurgia, Editura Stiintifica F.M.R., Nr.11, pp.22-27

Vetres, I.; Ionel, I.; Popescu, Fr. \& Dungan, L. (2009). Air Pollution Analysis, in Western Romania and Necessity of Complementary Vertical Resolved LIDAR Observation, Proceedings of the 3rd Workshop on Optoelectronic Techniques for Environmental Monitoring, Published by INOE, pp.32-36, ISSN: 2066-851, Bucharest, Romania

Wang, Y., W.; Yang, J. \& Jiang, W., M. (2009). Impact of large cities' expansion on air pollution, Proceedings of the International workshop on Geoscience and Remote Sensing, Vol. 1, pp.393-396, ISBN 978-0-7695-3563-0

Zolner, W.J.; Cieplinski, E.W. \& Dunlap, D.V. (1984). Measurement of Ambient Air $\mathrm{SO}_{2}$ Concentration using a pulsed Fluorescent Analyzer. Themo Electron Corporation, Waltham USA; deutsche Vertretung. Duisburg. Firmenprospekt 


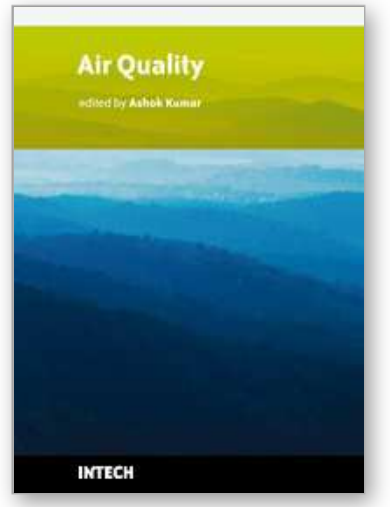

\author{
Air Quality \\ Edited by Ashok Kumar
}

ISBN 978-953-307-131-2

Hard cover, 382 pages

Publisher Sciyo

Published online 18, August, 2010

Published in print edition August, 2010

Air pollution is about five decades or so old field and continues to be a global concern. Therefore, the governments around the world are involved in managing air quality in their countries for the welfare of their citizens. The management of air pollution involves understanding air pollution sources, monitoring of contaminants, modeling air quality, performing laboratory experiments, the use of satellite images for quantifying air quality levels, indoor air pollution, and elimination of contaminants through control. Research activities are being performed on every aspect of air pollution throughout the world, in order to respond to public concerns. The book is grouped in five different sections. Some topics are more detailed than others. The readers should be aware that multi-authored books have difficulty maintaining consistency. A reader will find, however, that each chapter is intellectually stimulating. Our goal was to provide current information and present a reasonable analysis of air quality data compiled by knowledgeable professionals in the field of air pollution.

\title{
How to reference
}

In order to correctly reference this scholarly work, feel free to copy and paste the following:

Ioana lonel and Francisc Popescu (2010). Methods for Online Monitoring of Air Pollution Concentration, Air Quality, Ashok Kumar (Ed.), ISBN: 978-953-307-131-2, InTech, Available from:

http://www.intechopen.com/books/air-quality/methods-for-online-monitoring-of-air-pollution-concentration

\section{INTECH}

open science | open minds

\section{InTech Europe}

University Campus STeP Ri

Slavka Krautzeka 83/A

51000 Rijeka, Croatia

Phone: +385 (51) 770447

Fax: +385 (51) 686166

www.intechopen.com

\section{InTech China}

Unit 405, Office Block, Hotel Equatorial Shanghai No.65, Yan An Road (West), Shanghai, 200040, China 中国上海市延安西路65号上海国际贵都大饭店办公楼 405 单元 Phone: +86-21-62489820

Fax: +86-21-62489821 
(C) 2010 The Author(s). Licensee IntechOpen. This chapter is distributed under the terms of the Creative Commons Attribution-NonCommercialShareAlike-3.0 License, which permits use, distribution and reproduction for non-commercial purposes, provided the original is properly cited and derivative works building on this content are distributed under the same license. 